The effects of new entries on economic growth: a story on advanced and laggard sectors

\author{
By Vera Hansen
}

Supervised by Chia-Ying Chang

2009 


\section{Contents}

1 Introduction $\quad 3$

$\begin{array}{llr}2 & \text { The Environment } & 9\end{array}$

3 The Full Employment Constraint 20

4 Special Case $\quad 24$

5 Steady State Analysis $\quad 29$

6 Transitional Dynamics $\quad 31$

7 Conclusion $\quad 54$

8 References $\quad 55$ 


\title{
The effects of new entries on economic growth: a story on advanced and laggard sectors \\ By Vera Hansen
}

\begin{abstract}
The main goal of this thesis is to construct a theoretical model that provides an explanation for the relationship between growth and new entry that is consistent with empirical evidence. The model is a four sector endogenous growth model in which there is a technologically advanced and a technologically laggard consumption goods which are imperfect substitutes. The production of each good requires its own stock of human capital and physical capital. The accumulation of physical capital and human capital in each industry is modelled by a Cobb-Douglas production function. The main result of the model is that new entries have a positive effect on the fraction of the existing stock of human capital devoted to the accumulation of human capital in both the advanced and laggard sectors. However, this effect is stronger in the advanced sectors than in the laggard sectors. This result is consistent with empirical evidence.
\end{abstract}




\section{Introduction}

The main question that this thesis seeks to investigate is how new entry of foreign firms affects an economys growth rate. New entry is widely recognized as an important influence on economic growth. This paper takes a new look at this issue. It provides a theoretical analysis to investigate the effects of foreign firm entry on investment in human and physical capital and the economic growth rate.

In the existing literature there is no readily available theoretical analysis on the impact of new entries on the economic growth rate of an economy that has both laggard and advanced sectors. The contribution of this thesis therefore is to provide a detailed theoretical explanation of the effects on economic growth that is consistent with current empirical evidence.

The theoretical explanation is based on a four sector endogenous growth model with Cobb-Douglas production functions. The model describes a closed economy with two consumption goods that are imperfect substitutes, with one technology advanced and the other technology laggard. New entries affect the optimal levels of human capital devoted to accumulating human capital for the two goods in a systematically different way depending on the type of technology of the good.

The main result of the model is that new entries have a positive effect on the fraction of the existing stock of human capital devoted to the accumulation of human capital in both the advanced and the laggard sectors. However, under certain conditions, this effect is stronger in the advanced sectors, leading to a higher growth rate.

This result makes economic sense because, as the advanced good becomes more competitive, consumers will only demand the advanced good, so the laggard good becomes obsolete. Because eventually consumers will demand 
only the advanced good, it will be optimal to deplete the capital stocks specific to the laggard good by consuming more of it and investing less in future production. Also, advanced firms have a competitive advantage over laggard firms on a micro level. The advanced firms would want to retain their rents, and thus they would invest more in productivity to maintain their advanced position. These results have implications for country by country comparisons. Economies that start off as advanced will invest more and grow faster, thus increasing the economic gap between economies with different initial proportions of advanced or laggard sectors.

To help explain the model, the television industry is given as a relevant example. In recent years more and more people have been purchasing flat panel technologies. When it comes to buying flat panel televisions, consumers have two main choices; liquid crystal display (LCD) or plasma. LCD televisions create images by passing light through molecular structures of liquid crystals, whereas a plasma television uses a very different technology. It generates images by passing a high voltage through a low-pressure, electrically neutral, highly ionized atmosphere using the polarizing properties of light.

LCD technology is more advanced than plasma technology, as reflected by the lower power consumption of LCD televisions - a strong selling point in a time of environmentally conscious consumers. LCD technology also offers a better quality of picture. For these reasons, in this thesis LCDs are assumed to be the advanced good. Hence, a plasma television is considered to be the technology laggard good.

In the larger screen sizes of 42-inches and above, plasmas have been dominating the market because of their consistently lower prices; LCDs are approximately 50 percent more expensive than plasmas in the 50 -inch class. However, billions of dollars have been invested into research and develop- 
ment to make large LCDs more affordable. Sony, Sharp, and Samsung have also started building new LCD factories capable of mass producing larger screens. Investments have also been made to improve plasma technology.

Market researcher DisplaySearch in its Quarterly Worldwide FPD Forecast Report estimates that LCD TV display revenues will balloon to $\$ 91$ billion globally by 2010, while plasma screens will limp along with just under $\$ 16$ billion. Thus, the television industry provides a relevant example for this model. As producers of LCD televisions continue to invest in research and development to make production more efficient, they can price LCD televisions more competitively. If prices of LCDs come down and become comparable with those of plasmas, consumers will demand LCDs, as they are preferred and more advanced. This will make plasmas obsolete and LCDs will gain the entire market share. Therefore one would expect more investment in human capital specific to LCD than that specific to plasma technologies.

There is considerable empirical literature on the effects of new entry. Geroski (1995) provides a broad survey of the recent empirical work. One well known observation is that a high rate of new entry is often associated with high rates of innovation and increases in efficiency. The effects of entry may actually be more than just correcting displacements from static equilibria; entry may also be responsible for stimulating economic growth and development in markets. Accdording to Geroski (1995), numerous case studies have suggested that entry is often used as a vehicle for introducing new innovations. This is driven by the fact that incumbents are more interested in protecting existing rents than in seeking out new profit opportunities. Also, entry often encourages incumbents to drastically cut slack from their operations.

However, as Aghion et al (2006) highlight, it is not always the case that 
high entry rates induce high rates of innovation or productivity growth. They provide micro-data which suggests that there is a consistent heterogeneity across industries in the effects of foreign entry on average incumbent total factor productivity growth. There is a very large cross-section variation in entry, even though differences in entry between industries do not persist for very long. Rates of entry are rarely high or persistently low over time in particular industries, but rather entry seems to come in bursts that are not highly synchronized across sectors. Despite the relatively similar entry rates between industries, in some sectors entry has a strongly positive effect on growth, while in others it seems to depress incumbent total factor productivity growth. Positive effects tend to be found in industries that are technologically advanced relative to the world technology frontier. They are weak or even negative in technologically laggard industries. The main theoretical results found in this thesis are consistent with these empirical findings. Increased entry in both advanced and laggard sectors leads to higher investment in human capital and higher growth. However, this effect is much stronger in the advanced sectors.

Along with their empirical findings, Aghion et al (2006) also provide a theoretical model. Their main result is that firms that start off further behind the world technology frontier invest less in research and development than those firms closer to the world frontier. Their paper only focuses on the incentives of individual firms, not on the overall effects on economic growth. In contrast, this thesis models the empirical heterogeneity between advanced and laggard sectors in an endogenous growth model. This will fill the gap in the literature by describing a balanced growth path for the economys output, consumption and capital growth rates, rather than just focussing on firms individual incentives to innovate. This model also allows 
for both advanced and laggard firms to operate in the same industry, which is a realistic description of the televisons industry: investment continues to be made in plasma televisions even though LCD are more advanced.

Since this thesis uses an endogenous growth model, we will make use of the vast literature on endogenous growth. In particular, we borrow from the work of Romer (1986) and Lucas (1988) who analyse models in which the long-run growth rate is determined endogenously.

Rebelo (1991) studies a two-sector endogenous growth model with two Cobb-Douglas production functions, for goods and education. This thesis adapts his setting to include entry of new firms. This thesis also relates to the model of Lucas (1988), a two-sector endogenous growth model, in which human capital accumulation involves no physical capital. It serves as the basis for the special case covered in section 5 .

Other relevant literature includes recent theoretical advances that endogenize the process of technological improvements through continuing advances in methods of production and types and qualities of products. In particular, we need to mention the work of Schumpeter (1934) and Aghion and Howitt (1992), where progress shows up as quality improvements for an array of existing kinds of products.

The result that new entry has a stronger positive effect on the fraction of existing human capital devoted to the accumulation of human capital in the advanced sectors has direct implications for policy debates. These findings are relevant to the consideration of the costs and benefits of globalization and the discussion on entry regulation in different countries and industries. The analysis suggests that policies aiming at decreasing or removing entry barriers may foster productivity growth in the economy on average, but the effects will be stronger in the technologically developed sectors. 
This thesis is structured as follows: Section 2 follows with a description of the theoretical setting; an endogenous growth model with four Cobb-Douglas production functions. This is then followed by section 3, which introduces the full employment constraint. The next section covers a special case of the main model, where the production of human capital stock does not involve any physical capital, and therefore has a linear production function. Section 5 then analyzes the steady state values. The next section discusses the main results of the theoretical models. Section 7 concludes with a summary of the main results and possible directions of future research. 


\section{The Environment}

We consider a closed economy with a fixed number of identical, rational agents. There are also two different consumption goods, $C^{A}$ and $C^{L}$ which are imperfect substitutes. The consumption good $C^{A}$ is technologically advanced and the consumption good $C^{L}$ is technologically laggard.

Agents have real, per-capital consumption streams $C^{A}(t)$ and $C^{L}(t), t \geq$ 0 , of units of the consumption goods. Their preferences over (per-capita) consumption streams are given by the constant intertemporal elasticity utility function

$$
U\left(c^{A}, c^{L}\right)=\int_{t=0}^{\infty} e^{-\rho t} \frac{\left(c^{A}+\lambda c^{L}\right)^{1-\sigma}-1}{1-\sigma}
$$

where the discount rate $\rho$ and the coefficient of (relative) risk aversion $\sigma$ are both positive. The parameter $\lambda$ is assumed to be less than 1 and is given exogenously. The marginal rate of substitution between $C^{A}$ and $C^{L}$ is therefore $M R S_{A L}=\frac{1}{\lambda}$. An agent would be indifferent to giving up $\frac{1}{\lambda}(>1)$ units of the laggard good to obtain one additional unit of the advanced good. The technologically advanced good provides higher utility than the laggard good. In the example of the LCD and plasma televisions, the LCD television (the advanced good) is preferred to the plasma television (the laggard good); one LCD television provides more utility than a plasma television.

Production of each of the two goods is divided into total consumption, $C^{A}$ and $C^{L}$, and physical capital accumulation less physical capital depreciation. Let $K^{A}$ and $K^{L}$ denote the total stock of physical capital for the advanced and laggard sectors respectively, $\dot{K}^{A}$ and $\dot{K}^{L}$ be the rates of change of $K^{i}(i=$ $A, L)$, and $\delta$ be the rate of depreciation. Then the total output for the advanced good is $C^{A}+\dot{K}^{A}+\delta K^{A}$ and total output for the laggard sector 
is $C^{L}+\dot{K}^{L}+\delta K^{L}$. It is assumed that physical capital, $K^{A}$ and $K^{L}$, are not transferable between the two production of the goods, that is physical capital used to produce the consumption good in the advanced sector such as a factory or machinery cannot be used to produce the laggard consumption good and vise versa. For example, machinery used to produce LCD screens cannot be used to make a plasma screen.

This economy also has an cumulative stock of human capital specific to the production of each good, $H^{A}$ in the advanced sector and $H^{L}$ in the laggard sector. The stock of human capital reflects the general skill level of the workers. Individuals in the advanced sector allocate their time in the present period between producing for current consumption and investing in education that will affect their productivity, or skill level, in future periods. Workers in the laggard sector solve a similar problem. The production of advanced and laggard goods require specific knowledge, therefore human capital stocks, like physical capital, are not transferable between goods. In our example, the technology for LCD is very different to that of plasmas, therefore the human capital stock is very different and not transferable between the two sectors.

Each worker in the advanced sector devotes a fraction, $u$, of his non-leisure time to current production, and the remaining fraction $1-u$ to human capital accumulation, e.g. time spent attending training sessions and studying to increase their skills and knowledge. The effort, $1-u$, devoted to the accumulation of human capital must be linked to the rate of change in its level, $\dot{H}^{A}$. The laggard industry has a similar structure, with workers devoting fraction $v$ of their non-leisure time to production, and the remainding $1-v$ to human capital accumulation. This can be seen clearly in figure 1 on page 14 .

Physical capital, $K^{i}(i=A, L)$, also must be allocated between production of goods and human capital accumulation (e.g. providing equipment for 
advanced study such as a library or computers). In the advanced sector, a fraction $s$ of $K^{A}$ is devoted to production and the remainding $(1-s)$ is used in human capital accumulation. The laggard industry devotes fraction $q$ of $K^{L}$ to production and the remainder to human capital accumulation.

Production of goods depends on the levels of both physical and human capital specific to each industry, as well as on the exogenously given level of productivity, $\mathrm{B}(\mathrm{t})$, according to the following Cobb-Douglas production functions

$$
\begin{gathered}
Y^{A}=C^{A}+\dot{K}^{A}+\delta K^{A}=B^{A}\left(s K^{A}\right)^{\beta}\left(u H^{A}\right)^{1-\beta} \\
Y^{L}=C^{L}+\dot{K^{L}}+\delta K^{L}=B^{L}\left(q K^{L}\right)^{\theta}\left(v H^{L}\right)^{1-\theta}
\end{gathered}
$$

where $0<\beta<1$ and $0<\theta<1$. The parameters $\beta$ and $\theta$ are the output elasticities of physical capital for the advanced and laggard sectors, respectively. Thus, $(1-\beta)$ and $(1-\theta)$ are the output elasticities of human capital for the advanced and laggard sectors, respectively. These values are constants determined by the available technology and are exogenous to this model. Note that both technologies exhibit constant returns to scale. This means that if $H^{i}$ and $K^{i}$ each increase by $1 \%$, then $Y^{i}(i=A, L)$ will also increase by $1 \%$.

In our model output and human capital are generated by different production functions. This specification reflects a key aspect of education: it relies heavily on educated people as an input. The technology that relates the growth of human capital, $\dot{H}^{A}$, to the proportion of already attained human capital and physical capital devoted to acquiring more is a Cobb-Douglas production function.

However, in this economy the rate of change in the level of human capital 
is also influenced by new entrants into the economy. There are $N$ new entries to the economy at any given point in time. A fraction $\alpha$ of the new entries enter the advanced sector, while the remainder $1>\alpha>0$ joins the laggard sector. The economy is assumed to start with some initial level of human capital specific to each of the consumption goods, ie $H^{i}(0)>0(i=A, L)$. This assumption prevents the economy from falling into a poverty trap, where an economy never produces the advanced good and will never improve the quality of the consumption good.

Each new entry joins the market with an already established amount of human capital, $\xi^{i} H^{i}(i=A, L)$, where $\xi^{i}(i=A, L)$ is the proportion of the contribution of the new entry, and thus there is an extra contribution of $\alpha \xi^{A} N H^{A}$ and $(1-\alpha) \xi^{L} N H^{L}$ to each of the human capital pools. The contribution of the new entry to the human capital pools is illustrated by figure 1 below. 


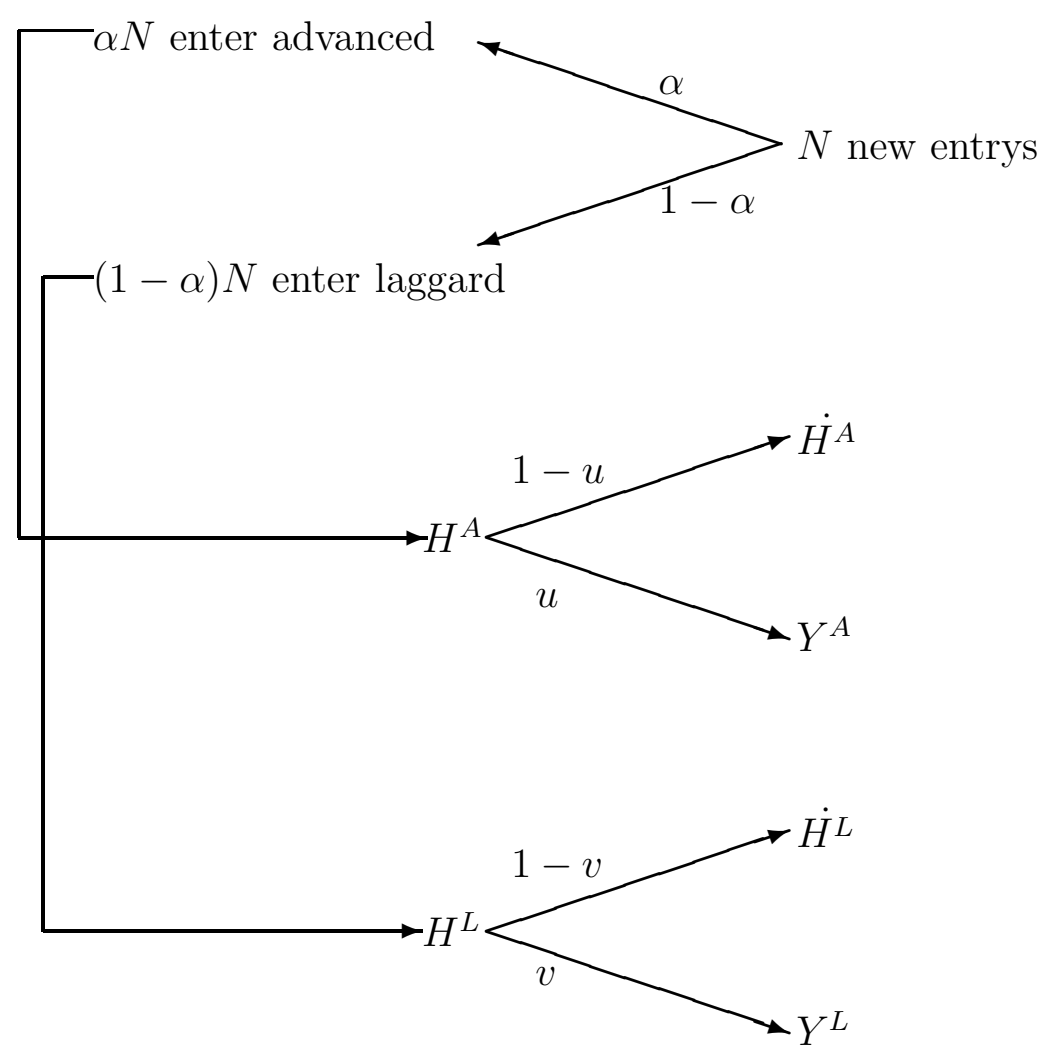

Figure 1 
Our assumptions imply the rate of change in the levels of the human capital stocks is

$$
\begin{gathered}
\dot{H}^{A}=\left[(1-s) K^{A}\right]^{\phi}\left[(1-u) H^{A}\right]^{1-\phi}+\alpha \xi^{A} N H^{A}-\delta H^{A} \\
\dot{H^{L}}=\left[(1-q) K^{L}\right]^{\mu}\left[(1-v) H^{L}\right]^{1-\mu}+(1-\alpha) \xi^{L} N H^{L}-\delta H^{L}
\end{gathered}
$$

where $0<\phi<1$ and $0<\mu<1$. We also assume that $\beta>\phi$ and $\theta>\mu$, as this reflects the empirically relevant case, because education tends to be more intensive in human capital than production of goods.

The four production functions are chosen to be Cobb-Douglas, so that there are constant returns to scale in both human and physical capital. This would deliver a balanced growth path for the steady state values of $C^{i}, K^{i}$, and $H^{i}$.

The resource allocation problem faced by this economy with four sectors is to choose a time path $C^{A}(t)$ and $C^{L}(t)$ for per-capita consumption, the fractions $u$ and $v$ of the human capital pools devoted to production, and the fractions $q$ and $s$ of the physical capital pools devoted to production.

Increasing physical and human capital has a shadow price. To find the allocation that maximizes the utility function (1) subject to the technologies (2a) - (3b), we use the current-value Hamiltonian J. It is defined as

$$
\begin{aligned}
J & =U\left(C^{A}, C^{L}\right) e^{\rho t}+\eta^{A}\left\{B^{A}\left(s K^{A}\right)^{\beta}\left(u H^{A}\right)^{1-\beta}-C^{A}-\delta K^{A}\right\} \\
& +\eta^{L}\left\{B^{L}\left(q K^{L}\right)^{\theta}\left(v H^{L}\right)^{1-\theta}-C^{A}-\delta K^{A}\right\} \\
& +\varphi^{A}\left\{\left[(1-s) K^{A}\right]^{\phi}\left[(1-u) H^{A}\right]^{1-\phi}+\alpha \xi^{A} N H^{A}-\delta H^{L}\right\} \\
& +\varphi^{L}\left\{\left[(1-q) K^{L}\right]^{\mu}\left[(1-v) H^{L}\right]^{1-\mu}+(1-\alpha) \xi^{L} N H^{L}-\delta H^{L}\right\}
\end{aligned}
$$


It is the sum of current-period utility, the rates of increase of capital for the advanced and laggard goods, $\dot{K}^{A}$ and $\dot{K}^{L}$, valued at their shadow prices, $\eta^{A}$ and $\eta^{L}$, and the rates of increase in human capital, $\dot{H}^{A}$ and $\dot{H}^{L}$, valued at their shadow prices $\varphi^{A}$ and $\varphi^{L}$. An optimal allocation must maximize expression $\mathrm{J}$ at each date $t$, provided the shadow prices are chosen correctly.

The first order conditions for $C^{A}, C^{L}, s, q, u$, and $v$ are;

$$
\begin{gathered}
\frac{d U(C)}{d C^{A}}=e^{\rho t} \eta^{A} \\
\frac{d U(C)}{d C^{L}}=e^{\rho t} \eta^{L} \\
K^{A}\left\{\eta^{A} \beta B^{A}\left(s K^{A}\right)^{\beta-1}\left(u H^{A}\right)^{1-\beta}-\varphi^{A} \phi\left[(1-s) K^{A}\right]^{\phi-1}\left[(1-u) H^{A}\right]^{1-\phi}\right\}=0 \\
K^{L}\left\{\eta^{L} \theta B^{L}\left(q K^{L}\right)^{\theta-1}\left(v H^{A}\right)^{1-\theta}-\varphi^{L} \mu\left[(1-q) K^{L}\right]^{\mu-1}\left[(1-v) H^{L}\right]^{1-\mu}\right\}=0 \\
H^{A}\left\{\eta^{A}(1-\beta) B^{A}\left(s K^{A}\right)^{\beta}\left(u H^{A}\right)^{-\beta}-\varphi^{A}(1-\phi)\left[(1-s) K^{A}\right]^{\phi}\left[(1-u) H^{A}\right]^{-\phi}\right\}=0 \\
H^{L}\left\{\eta^{L}(1-\theta) B^{L}\left(q K^{L}\right)^{\theta}\left(v H^{L}\right)^{-\theta}-\varphi^{L}(1-\mu)\left[(1-v) K^{L}\right]^{\mu}\left[(1-v) H^{L}\right]^{-\mu}\right\}=0
\end{gathered}
$$

The conditions $\dot{\varphi^{A}}=-\frac{\partial J}{\partial H^{A}}, \dot{\varphi^{L}}=-\frac{\partial J}{\partial H^{L}}, \dot{\eta^{A}}=-\frac{\partial J}{\partial K^{A}}$, and $\dot{\eta^{L}}=-\frac{\partial J}{\partial K^{L}}$ imply; 


$$
\begin{gathered}
\frac{\dot{\varphi^{A}}}{\varphi^{A}}=-\frac{\eta^{A}}{\varphi^{A}} B^{A}(1-\beta)(u)\left(s K^{A}\right)^{\beta}\left(u H^{A}\right)^{-\beta} \\
-(1-\phi)(1-u)\left[(1-s) K^{A}\right]^{\phi}\left[(1-u) H^{A}\right]^{-\phi}-\alpha \xi^{A} N+\delta \\
\frac{\dot{\varphi^{L}}}{\varphi^{L}}=-\frac{\eta^{L}}{\varphi^{L}} B^{L}(1-\theta)(v)\left(q K^{L}\right)^{\theta}\left(v H^{L}\right)^{-\theta} \\
\quad-(1-\mu)(1-v)\left[(1-q) K^{L}\right]^{\mu}\left[(1-v) H^{L}\right]^{-\mu}-(1-\alpha) \xi^{L} N+\delta \\
\frac{\dot{\eta^{A}}}{\eta^{A}}=-B^{A} \beta s\left(s K^{A}\right)^{\beta-1}\left(u H^{A}\right)^{1-\beta}+\delta-\frac{\varphi^{A}}{\eta^{A}} \phi(1-s)\left[(1-s) K^{A}\right]^{\phi-1}\left[(1-u) H^{A}\right]^{1-\phi} \\
\frac{\dot{\eta^{L}}}{\eta^{L}}=-
\end{gathered}
$$

The above first order conditions determine the growth rates of consumption of the two goods. Differentiating $(5 a)$ and $(5 b)$ with respect to time gives expressions for $\dot{\eta}^{A}$ and $\eta^{L}$. Substituting these expressions into $(9 a)$ and (9b) and rearranging yields

$$
\begin{aligned}
& \frac{\dot{C}^{A}}{C^{A}}=\left[\frac{\left(C^{A}+\lambda C^{L}\right)}{\sigma C^{A}}\right]\left[\beta B^{A}\left(s K^{A}\right)^{\beta-1}\left(u H^{A}\right)^{1-\beta}-\delta-\rho\right] \\
& \frac{\dot{C}^{L}}{C^{L}}=\left[\frac{\left(C^{A}+\lambda C^{L}\right)}{\sigma \lambda C^{L}}\right]\left[\theta B^{L}\left(q K^{L}\right)^{\theta-1}\left(v H^{L}\right)^{1-\theta}-\delta-\rho\right]
\end{aligned}
$$

Note that the growth rate of consumption is proportional to the marginal product of physical capital in the production of goods less $\rho+\delta$.

Efficient production decisions are characterized by two conditions. The first is static: it defines the optimal allocation of the existing stock of physical 
capital and the available efficiency units of labor across the two activities. In an efficient allocation, the marginal product of physical and human capital measured in terms of units of physical capital has to be equated in the two sectors. Let us define $P^{i} \equiv \frac{\varphi^{i}}{\eta^{i}}$, where $P^{i}$ is the relative value of human capital in terms of physical capital in sector $i$. Using the first order conditions for $s$ and $u, q$ and $v$ can be written as;

$$
\begin{gathered}
B^{A} \beta\left(s K^{A}\right)^{\beta-1}\left(u H^{A}\right)^{1-\beta}=P^{A} \phi\left[(1-s) K^{A}\right]^{\phi-1}\left[(1-u) H^{A}\right]^{1-\phi} \\
B^{A}(1-\beta)\left(s K^{A}\right)^{\beta}\left(u H^{A}\right)^{-\beta}=P^{A}(1-\phi)\left[(1-s) K^{A}\right]^{\phi}\left[(1-u) H^{A}\right]^{-\phi} \\
B^{L} \theta\left(q K^{L}\right)^{\theta-1}\left(v H^{L}\right)^{1-\theta}=P^{L} \mu\left[(1-q) K^{L}\right]^{\mu-1}\left[(1-v) H^{L}\right]^{1-\mu} \\
B^{L}(1-\theta)\left(q K^{L}\right)^{\theta}\left(v H^{L}\right)^{-\theta}=P^{L}(1-\mu)\left[(1-q) K^{L}\right]^{\mu}\left[(1-v) H^{L}\right]^{-\mu}
\end{gathered}
$$

Eliminating $P^{A}$ from (11a) and (11b), and applying the same procedure to $P^{L}$ in $(12 \mathrm{a})$ and $(12 \mathrm{~b})$ yields the requirement of efficiency in production. The marginal rate of transformation must be equated in the two sectors:

$$
\begin{aligned}
& \left(\frac{\phi}{1-\phi}\right)\left(\frac{s}{1-s}\right)=\left(\frac{\beta}{1-\beta}\right)\left(\frac{u}{1-u}\right) \\
& \left(\frac{\mu}{1-\mu}\right)\left(\frac{q}{1-q}\right)=\left(\frac{\theta}{1-\theta}\right)\left(\frac{v}{1-v}\right)
\end{aligned}
$$

Solving (11a) and (11b) for $P^{A}$ and $P^{L}$ respectively, and then using (13a) and $(13 b)$, we get $P^{A}$ and $P^{L}$ as functions of $\frac{s K^{A}}{u H^{A}}$ and $\frac{q K^{L}}{v H^{L}}$. 


$$
\begin{aligned}
P^{A} & =B^{A}\left(\frac{\beta}{\phi}\right)^{\phi}\left[\frac{1-\beta}{1-\phi}\right]^{1-\phi}\left[\frac{s K^{A}}{u H^{A}}\right]^{\beta-\phi} \\
P^{L} & =B^{L}\left(\frac{\theta}{\mu}\right)^{\mu}\left[\frac{1-\theta}{1-\mu}\right]^{1-\mu}\left[\frac{q K^{L}}{v H^{L}}\right]^{\theta-\mu}
\end{aligned}
$$

The second efficiency condition is dynamic: it refers to the decision of investing in physical capital versus human capital. Having an extra unit of physical capital is worth its net marginal product in the production sector for the advanced and laggard goods, respectively.

$$
\begin{aligned}
& r^{A}=B^{A} \beta\left(s K^{A}\right)^{\beta-1}\left(u H^{A}\right)^{1-\beta}-\delta \\
& r^{L}=B^{L} \theta\left(q K^{L}\right)^{\theta-1}\left(v H^{L}\right)^{1-\theta}-\delta
\end{aligned}
$$

Alternatively, instead of investing in one more unit of capital, we could accumulate $\frac{1}{P^{i}}$ units of human capital, which yields a net return expressed in terms of physical capital

$$
\begin{gathered}
r^{A *}=(1-\phi)\left[(1-s) K^{A}\right]^{\phi}\left[(1-u) H^{A}\right]^{-\phi}+\alpha \xi^{A} N-\delta+\frac{\dot{P^{A}}}{P^{A}} \\
r^{L *}=(1-\mu)\left[(1-q) K^{L}\right]^{\mu}\left[(1-v) H^{L}\right]^{-\mu}+(1-\alpha) \xi^{L} N-\delta+\frac{\dot{P^{L}}}{P^{L}}
\end{gathered}
$$

for the advanced and laggard goods, respectively.

The rates of return from the activities in each goods must be the same, so $r^{i}=r^{i *}$.

Solving equations (16a) and (16b) for $\frac{P^{i}}{P^{i}}$ and writing (15a) and (15b) in terms of $P^{i}$ alone gives 


$$
\begin{gathered}
\frac{\dot{P} A}{P^{A}}=\left(B^{A}\right)^{\frac{1-\phi}{\beta-\phi}} \beta^{\frac{\beta(1-\phi)}{\beta-\phi}} \phi^{\frac{\phi(\beta-1)}{\beta-\phi}}\left(\frac{1-\phi}{1-\beta}\right)^{\frac{(1-\phi)(\beta-1)}{\beta-\phi}}\left(p^{A}\right)^{\frac{\beta-1}{\beta-\phi}} \\
-\left(B^{A}\right)^{\frac{-\phi}{\beta-\phi}}\left(\frac{\phi}{\beta}\right)^{\frac{\phi(\phi-1)+\beta}{\beta-\phi}}(1-\phi)\left(\frac{1-\phi}{1-\beta}\right)^{\frac{\phi(1-\beta)}{\beta-\phi}}\left(P^{A}\right)^{\frac{\phi}{\beta-\phi}}-\alpha \xi^{A} N \\
\frac{\dot{P^{L}}}{P^{L}}=\left(B^{L}\right)^{\frac{1-\mu}{\theta-\mu}} \theta^{\frac{\theta(1-\mu)}{\theta-\mu}} \mu^{\frac{\mu(\theta-1)}{\theta-\mu}}\left(\frac{1-\mu}{1-\theta}\right)^{\frac{(1-\mu)(\theta-1)}{\theta-\mu}}\left(p^{L}\right)^{\frac{\theta-1}{\theta-\mu}} \\
-\left(B^{L}\right)^{\frac{-\mu}{\theta-\mu}}\left(\frac{\mu}{\theta}\right)^{\frac{\mu(\mu-1)+\theta}{\theta-\mu}}(1-\mu)\left(\frac{1-\mu}{1-\theta}\right)^{\frac{\mu(1-\theta)}{\theta-\mu}}\left(P^{L}\right)^{\frac{\mu}{\theta-\mu}}-(1-\alpha) \xi^{L} N
\end{gathered}
$$

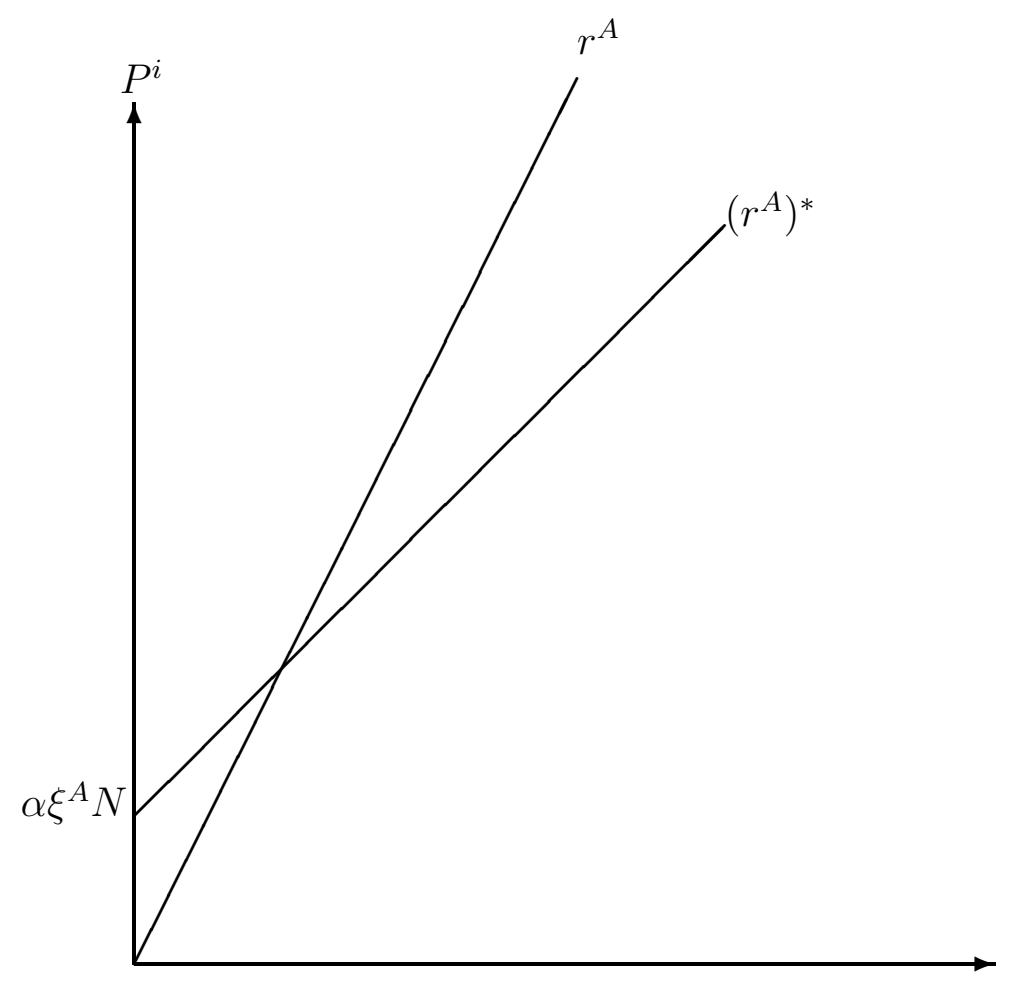

Therefore, to have interior solutions for $P^{A}$ (or $P^{L}$ ), the slope of $\left(r^{A}\right)^{*}$ (or $\left(r^{L}\right)^{*}$ ) must be flatter than that of $r^{A}$ (or $\left.r^{L}\right)$. 


\section{The Full Employment Constraint}

We now use a full employment constraint similar to that of Bond et al (1996). Since we have two sectors, this will enable us to solve for the growth rates. We define $X^{i}$ as the output of the goods sector $(i=A, L)$ and $Y^{i}$ as the output of the education sector. Then

$$
\begin{gathered}
X^{A}=u H^{A} B^{A}\left(k_{x}^{A}\right)^{\beta} \\
X^{L}=v H^{L} B^{L}\left(k_{y}^{L}\right)^{\theta} \\
Y^{A}=(1-u) H^{A}\left(k_{y}^{A}\right)^{\phi} \\
Y^{L}=(1-v) H^{L}\left(k_{y}^{L}\right)^{\mu}
\end{gathered}
$$

where $k_{x}^{A} \equiv \frac{s K^{A}}{u H^{A}}$ is the physical capital to human capital ratio in the goods sector and $k_{y}^{A} \equiv \frac{(1-s) K^{A}}{(1-u) H^{A}}$ is the physical capital to human capital ratio in the education sector for the advanced good, while $k_{x}^{L} \equiv \frac{s K^{L}}{u H^{L}}$ and $k_{y}^{L} \equiv \frac{(1-s) K^{L}}{(1-u) H^{L}}$ are the corresponding ratios for the laggard good. Next we rewrite the first order conditions for $s, u, q$ and $v$, requiring the real rate of return on physical capital and human capital to be equalized across sectors. The market rental rate on capital is defined as $r^{A} \equiv \beta B^{A}\left(k_{x}^{A}\right)^{\beta-1}$ in the advanced good and as $r^{L} \equiv B^{L} \theta\left(k_{x}^{L}\right)^{\theta-1}$ in the laggard good. We also define the market wage expressed in units of goods as $w^{A} \equiv B^{A}\left(k_{x}^{A}\right)^{\beta}(1-\beta)$ and $w^{L} \equiv B^{L}\left(k_{x}^{L}\right)^{\theta}(1-\theta)$ for the advanced and laggard goods, respectively.

Totally differentiating equations (18a)-(19b) and applying Cramers rule yields 


$$
\begin{aligned}
& \frac{d k_{x}^{A}}{d P^{A}}=\frac{k_{x}^{A}}{\left(k_{y}^{A}\right)}\left[\frac{k_{y}^{A}}{(1-\beta)}+\frac{k_{x}^{A}}{\beta}\right] \\
& \frac{d k_{x}^{L}}{d P^{L}}=\frac{k_{x}^{L}}{\left(k_{y}^{L}\right)}\left[\frac{k_{y}^{L}}{(1-\theta)}+\frac{k_{x}^{l}}{\theta}\right] \\
& \frac{d k_{y}^{A}}{d P^{A}}=\frac{B^{A}\left(k_{x}^{A}\right)^{\beta}}{(\phi-1) \phi\left(k_{y}^{A}\right)^{\phi-2}\left(k_{y}^{A}-k_{x}^{A}\right)} \\
& \frac{d k_{y}^{L}}{d P^{L}}=\frac{B^{L}\left(k_{x}^{L}\right)^{\theta}}{\left(k_{y}^{L}-k_{x}^{L}\right)(\mu-1) \mu\left(k_{y}^{L}\right)^{\mu-2}} \\
& \frac{d r^{A}}{d P^{A}}=\beta(\beta-1) B^{A}\left(k_{x}^{A}\right)^{\beta-1} \\
& \frac{d r^{L}}{d P^{L}}=B^{L} \theta(\theta-1)\left(k_{x}^{L}\right)^{\theta-2} k_{x}^{L}(P) \\
& \frac{d w^{A}}{d P^{A}}=\left(k_{x}^{A}\right)^{2}(1-\phi) \phi\left(k_{y}^{A}\right)^{\phi-2} \\
& \frac{d w^{L}}{d P^{L}}=\left(k_{x}^{L}\right)^{2}(1-\mu) \mu\left(k_{y}^{L}\right)^{\mu-2} k_{x}^{L}(P)
\end{aligned}
$$

These derivatives can be combined with the full employment condition to derive the allocation of human capital between sectors and the scaled output of each sector. Let $k^{i} \equiv \frac{K^{i}}{H^{i}}(i=A, L)$ be the aggregate factor proportion. Full employment requires that $u k_{x}^{A}(P)+(1-u) k_{y}^{A}(P)=k^{A}$ and $v k_{x}^{L}(P)+(1-v) k_{y}^{L}(P)=k^{L}$. This implies

$$
\begin{aligned}
& u\left(P^{A}, k^{A}\right)=\frac{\left[k^{A}-k_{y}^{A}\right]}{\left[k_{x}^{A}-k_{y}^{A}\right]} \\
& v\left(P^{L}, k^{L}\right)=\frac{\left[k^{L}-k_{y}^{L}\right]}{\left[k_{x}^{L}-k_{y}^{L}\right]}
\end{aligned}
$$




$$
\begin{aligned}
x^{A}\left(P^{A}, k^{A}\right) & =\frac{B^{A}\left(k_{y}^{A}\right)^{\beta}\left[k^{A}-k_{y}^{A}\right]}{\left[k_{x}^{A}-k_{y}^{A}\right]} \\
x^{L}\left(P^{L}, k^{L}\right) & =\frac{B^{L}\left(k_{y}^{L}\right)^{\theta}\left[k^{L}-k_{y}^{L}\right]}{\left[k_{x}^{L}-k_{y}^{L}\right]} \\
y^{A}\left(P^{A}, k^{A}\right) & =\left[1-\frac{\left[k^{A}-k_{y}^{A}\right]}{\left[k_{x}^{A}-k_{y}^{A}\right]}\right]\left(k_{y}^{A}\right)^{\phi} \\
y^{L}\left(P^{L}, k^{L}\right) & =\left[1-\frac{\left[k^{L}-k_{y}^{L}\right]}{\left[k_{x}^{L}-k_{y}^{L}\right]}\right]\left(k_{y}^{L}\right)^{\mu}
\end{aligned}
$$

where $k_{x}^{i}$ and $k_{y}^{i}$ are functions of prices.

Bond et al (1995) prove that existence and uniqueness of a non-degenerated balanced growth path in which $C^{i}, H^{i}$, and $K^{i}$ all grow at the common rate $\gamma^{i}$ require three conditions to be met.

The first condition is that the maximal attainable rate of consumption growth satisfies $\rho>(1-\sigma){\frac{\dot{C}^{i}}{C^{i}}}_{\max }(i=A, L)$. This means that $\sigma$ cannot be too small.

The second condition is imposed on the technology. It ensure the existence of an equilibrium in which investment in both types of capital is profitable. This condition will be satisfied in our model because both sectoral production functions are Cobb-Douglas. Therefore, the factor return differentials are unbounded, and so the condition is met automatically.

The final condition for nondegenerate growth requires; $r^{i *}-\delta>\rho$. This condition ensures that the sectors are sufficiently productive to generate $\frac{\dot{C}^{i}}{C^{i}}>$ 0 at the price consistent with balanced growth.

Since our model satisfies the above conditions, the balanced growth paths of the economys advanced and laggard sectors exist and are unique. 
Using equations (10a) and (10b), we obtain the balanced growth path for each sector.

$$
\begin{aligned}
& \gamma^{A}=\left(\frac{\left(C^{A}+\lambda C^{L}\right)}{\sigma C^{A}}\right)\left[\beta B^{A}\left(\frac{P^{A}}{B^{A}}\left(\frac{\phi}{\beta}\right)^{\phi}\left(\frac{1-\phi}{1-\beta}\right)^{1-\phi}\right)^{\frac{\beta-1}{\beta-\phi}}-\delta-\rho\right] \\
& \gamma^{L}=\left(\frac{\left(C^{A}+\lambda C^{L}\right)}{\sigma \lambda C^{L}}\right)\left[\theta B^{L}\left(\frac{P^{L}}{B^{L}}\left(\frac{\mu}{\theta}\right)^{\mu}\left(\frac{1-\mu}{1-\theta}\right)^{1-\mu}\right)^{\frac{\theta-1}{\theta-\mu}}-\delta-\rho\right]
\end{aligned}
$$

These are the rates at which $Y^{i}, C^{i}, K^{i}$, and $H^{i}$ grow in the steady state. The absolute levels of $K^{i}, H^{i}$, and $C^{i}$ will not influence the growth rates because the system can be written in terms of ratios. 


\section{Special Case}

In the extreme case where production of human capital is intensive in the existing human capital stock and involves no physical capital, the values of $\phi$ and $\mu$ will be equal to zero. This setup is similar to that of the Lucas (1988) model, where the growth of human capital, $\dot{H}^{A}$ is linear in the level of existing human capital and in education effort.

The production functions from (2)-(5) can be simplified to;

$$
\begin{aligned}
\dot{H}^{A} & =\left[(1-u)+\alpha \xi^{A} N\right] H^{A}-\delta H^{A} \\
\dot{H}^{L} & =\left[(1-v)+(1-\alpha) \xi^{L} N\right] H^{L}-\delta H^{L} \\
Y^{A} & =C^{A}+\dot{K}^{A}+\delta K^{A}=B^{A}\left(K^{A}\right)^{\beta}\left(u H^{A}\right)^{1-\beta} \\
Y^{L} & =C^{L}+\dot{K}^{L}+\delta K^{L}=B^{L}\left(K^{L}\right)^{\theta}\left(v H^{L}\right)^{1-\theta}
\end{aligned}
$$

According to (28a) and (28b), if no effort is devoted to human capital accumulation $[u(t)=1]$ and $[v(t)=1]$, then only new entries will contribute to new human capital $H^{i}(i=A, L)$. If all effort is devoted to this purpose $[u(t)=0]$ and $[v(t)=0], H^{A}$ and $H^{L}$ grow at the maximum rates. In between these extremes, there are no diminishing returns to the stock through effort devoted to human capital accumulation; a given percentage increase in either $H^{A}$ or $H^{L}$ requires the same effort, no matter what level of $H^{A}$ and $H^{L}$ has already been attained.

The modified current-value Hamiltonian is 


$$
\begin{aligned}
J & =U\left(C^{A}, C^{L}\right) e^{-\rho t}+\eta^{A}\left\{B^{A}\left(K^{A}\right)^{\beta}\left(u H^{A}\right)^{1-\beta}-C^{A}-\delta K^{A}\right\} \\
& +\eta^{L}\left\{B^{L}\left(K^{L}\right)^{\theta}\left(v H^{L}\right)^{1-\theta}-C^{L}-\delta K^{L}\right\} \\
& +\varphi^{A}\left\{\left[(1-u)+\alpha \xi^{A} N\right] H^{A}-\delta H^{A}\right\} \\
& +\varphi^{L}\left\{\left[(1-v)+(1-\alpha) \xi^{L} N\right] H^{L}-\delta H^{L}\right\}
\end{aligned}
$$

It is convenient to define the following ratios: $\omega^{A} \equiv \frac{K^{A}}{H^{A}}, \omega^{L} \equiv \frac{K^{L}}{H^{L}}$ , $\chi^{A} \equiv \frac{C^{A}}{K^{A}}, \chi^{L} \equiv \frac{C^{L}}{K^{L}}$ Using these definitions, we get expressions for the growth rates of $K^{A}, K^{L}, H^{A}$, and $H^{L}$.

$$
\begin{aligned}
& \frac{\dot{K^{A}}}{K^{A}}=B^{A} u^{1-\beta}\left(\omega^{A}\right)^{\beta-1}-\chi^{A}-\delta \\
& \frac{\dot{K}^{L}}{K^{L}}=B^{L} v^{1-\theta}\left(\omega^{L}\right)^{\theta-1}-\chi^{L}-\delta \\
& \frac{\dot{H}^{A}}{H^{A}}=(1-u)+\alpha \xi^{A} N-\delta \\
& \frac{\dot{H}^{L}}{H^{L}}=(1-v)+(1-\alpha) \xi^{L} N-\delta
\end{aligned}
$$

Hence, the growth rates of $\omega^{A}$ and $\omega^{L}$ are given by

$$
\begin{gathered}
\frac{\dot{\omega^{A}}}{\omega^{A}}=\frac{\dot{K^{A}}}{K^{A}}-\frac{\dot{H^{A}}}{H^{A}}=B^{A} u^{1-\beta}\left(\omega^{A}\right)^{\beta-1}-\chi^{A}-(1-u)-\alpha \xi^{A} N \\
\frac{\dot{\omega^{L}}}{\omega^{L}}=\frac{\dot{K^{L}}}{K^{L}}-\frac{\dot{H^{L}}}{H^{L}}=B^{L} v^{1-\theta}\left(\omega^{L}\right)^{\theta-1}-\chi^{L}-(1-v)-(1-\alpha) \xi^{L} N
\end{gathered}
$$

From eqation (30), the first order conditions for $C^{A}, C^{L}, v$, and $u$ can be 
used to give the following;

$$
\begin{aligned}
& \eta^{A} e^{\rho t}=\frac{d U\left(C^{A}+\lambda C^{L}\right)}{d C^{A}} \\
& \eta^{L} e^{\rho t}=\frac{d U\left(C^{A}+\lambda C^{L}\right)}{d C^{L}} \\
& \frac{\eta^{A}}{\varphi^{A}}=\frac{u^{\beta}\left(\omega^{A}\right)^{-\beta}}{(1-\beta) B^{A}} \\
& \frac{\eta^{L}}{\varphi^{L}}=\frac{v^{\theta}\left(\omega^{L}\right)^{-\theta}}{(1-\theta) B^{L}}
\end{aligned}
$$

The other relevant conditions; $\dot{\varphi}^{A}=-\frac{\partial J}{\partial H^{A}}, \dot{\varphi}^{L}=-\frac{\partial J}{\partial H^{L}}, \dot{\eta}^{A}=-\frac{\partial J}{\partial K^{A}}$, and $\dot{\eta}^{L}=-\frac{\partial J}{\partial H^{L}}$ imply that;

$$
\begin{gathered}
\frac{\dot{\varphi} A}{\varphi^{A}}=-\left(\frac{\eta^{A}}{\varphi^{A}}\right) B^{A}\left(\omega^{A}\right)^{\beta}(1-\beta) u^{1-\beta}-\left[1-u+\alpha \xi^{A} N\right]+\delta \\
\frac{\dot{\varphi^{L}}}{\varphi^{L}}=-\frac{\eta^{L}}{\varphi^{L}}(1-\theta) B^{L} v^{1-\theta}\left(\omega^{L}\right)^{\theta}-(1-v)-(1-\alpha) \xi^{L} N+\delta \\
\frac{\dot{\eta^{A}}}{\eta^{A}}=-B^{A} \beta\left(\omega^{A}\right)^{\beta-1} u^{1-\beta}+\delta \\
\frac{\eta^{L}}{\eta^{L}}=-\theta B^{L} v^{1-\theta}\left(\omega^{L}\right)^{\theta-1}+\delta
\end{gathered}
$$

The above conditions can be used to obtain the growth rates of consumption for the two goods. Differentiating equations (34a) and (34b) with respect to time gives expressions for $\eta^{A}$ and $\dot{\eta}^{L}$. If we substitute these expressions for (37a) and (37b), with some rearranging we get condition for the consumption growth rates:

$$
\frac{\dot{C}^{A}}{C^{A}}=\frac{\left(C^{A}+\lambda C^{L}\right)}{\sigma C^{A}}\left[\beta B^{A} u^{1-\beta}\left(\omega^{A}\right)^{-(1-\beta)}-\delta-\rho\right]
$$




$$
\frac{\dot{C}^{L}}{C^{L}}=\frac{\left(C^{A}+\lambda C^{L}\right)}{\sigma \lambda C^{L}}\left[\theta B^{L} v^{1-\theta}\left(\omega^{L}\right)^{-(1-\theta)}-\delta-\rho\right]
$$

The growth rates of $\chi^{A}$ and $\chi^{L}$ follow from equations (31a), (31b) (38a) and (38b).

$$
\begin{aligned}
\frac{\dot{\chi^{A}}}{\chi^{A}} & =\frac{\dot{C^{A}}}{C^{A}}-\frac{\dot{K}}{K^{A}} \\
& =\frac{\left(C^{A}+\lambda C^{L}\right)}{\sigma C^{A}}\left[\beta B^{A} u^{1-\beta}\left(\omega^{A}\right)^{-(1-\beta)}-\delta-\rho\right]+\chi^{A}+\delta-B^{A} u^{1-\beta}\left(\omega^{A}\right)^{\beta-1}
\end{aligned}
$$

$$
\begin{aligned}
\frac{\dot{\chi^{L}}}{\chi^{L}} & =\frac{\dot{c^{L}}}{c^{L}}-\frac{\dot{K}}{K^{L}} \\
& =\frac{\left(c^{A}+\lambda c^{L}\right)}{\sigma \lambda c^{L}}\left[\theta B^{L} v^{1-\theta}\left(\omega^{L}\right)^{-(1-\theta)}-\delta-\rho\right]+\chi^{L}+\delta-B^{L} v^{1-\theta}\left(\omega^{L}\right)^{\theta-1}
\end{aligned}
$$

If we differentiate equations $(35 a)$ and $(35 b)$ with respect to time, substitute $\dot{\eta}^{A}$ and $\dot{\eta}^{L}$ from equations $(37 a)$ and $(37 b), \dot{\varphi}^{A}$ and $\dot{\varphi}^{L}$ from equations (36a) and $(36 b)$, and $\frac{\dot{\omega}^{A}}{\omega^{A}}$ and $\frac{\dot{\omega}^{L}}{\omega^{L}}$ from $(33 a)$ and (33b), after simplifying we get

$$
\begin{gathered}
\frac{\dot{u}}{u}=\frac{\left[1+\alpha \xi^{A} N\right]}{\beta}-\chi^{A}-\left[(1-u)+\alpha \xi^{A} N\right] \\
\frac{\dot{v}}{v}=\frac{\left[1+(1-\alpha) \xi^{L} N\right]}{\theta}-\chi^{L}-\left[(1-v)+(1-\alpha) \xi^{L} N\right]
\end{gathered}
$$

The variables $\varphi^{A}$ and $\varphi^{L}$ represent the values of an unit of human capital, $\eta^{A}$ and $\eta^{L}$ represent the values of an incremental unit of physical capital. The term $P^{i} \equiv \frac{\varphi^{i}}{\eta^{i}}$ is the relative price of human capital in terms of goods. Then using equations (36a)-(37b) we can find $\frac{\dot{P^{A}}}{P^{A}}$ and $\frac{\dot{P^{L}}}{P^{L}}$ : 


$$
\begin{gathered}
\frac{\dot{P^{A}}}{P^{A}} \equiv \frac{\dot{\varphi^{A}}}{\varphi^{A}}-\frac{\dot{\eta^{A}}}{\eta^{A}}=-\left[1+\alpha \xi^{A} N\right]+B^{A} \beta\left(\omega^{A}\right)^{\beta-1} u^{1-\beta} \\
\frac{\dot{P^{L}}}{P^{L}} \equiv \frac{\dot{\eta^{L}}}{\eta^{L}}-\frac{\dot{\varphi^{L}}}{\varphi^{L}}=-\left[1+(1-\alpha) \xi^{L} N\right]+\theta B^{L} v^{1-\theta}\left(\omega^{L}\right)^{\theta-1}
\end{gathered}
$$

Equations (41a) and (41b) deliver the growth rates of $P^{A}$ and $P^{L}$ respectively. 


\section{$5 \quad$ Steady State Analysis}

Conditions (33a), (33b), (39a), (39b), (40a), and (40b) form a system of six differential equations in the variables $\omega^{A}, \omega^{L}, \chi^{A}, \chi^{L}, u$, and, $v$. Assume that the initial values of the state variables $\omega^{A}$ and $\omega^{L}$ are $\omega^{A}(0)$ and $\omega^{L}(0)$. The steady state of this system can be characterised by setting the six time derivatives to zero. This yields

$$
\begin{aligned}
& \left(\chi^{A}\right)^{*}=\frac{\left(1+\alpha \xi^{A} N\right)\left(\pi^{A}-1\right)}{\beta}+\pi^{A}(\delta+\rho)-\delta \\
& \left(\chi^{L}\right)^{*}=\frac{\left(1+(1-\alpha) \xi^{L} N\right)\left(\pi^{L}-1\right)}{\theta}+\pi^{L}(\delta+\rho)-\delta \\
& u^{*}=\frac{-\left[1+\alpha \xi^{A} N\right]}{\beta}\left[\beta+\pi^{A}\right]+\pi^{A}(\delta+\rho)-\delta \\
& v^{*}=\frac{-\left[1+(1-\alpha) \xi^{L} N\right]}{\theta}\left[\theta+\pi^{L}\right]+\pi^{L}(\delta+\rho)-\delta \\
& \left(\omega^{A}\right)^{*}=\left[\frac{-\left(1+\alpha \xi^{A} N\right)}{\beta B^{A}}\right]^{\frac{1}{\beta-1}}\left[\frac{\left[1+\alpha \xi^{A} N\right]}{\beta}\left[\beta+\pi^{A}\right]+\pi^{A}(\delta+\rho)-\delta\right] \\
& \left(\omega^{L}\right)^{*}=\left[\frac{-\left(1+(1-\alpha) \xi^{L} N\right)}{\theta B^{L}}\right]^{\frac{1}{\theta-1}}\left[\frac{\left[1+(1-\alpha) \xi^{L} N\right]}{\theta}\left[\theta+\pi^{L}\right]+\pi^{L}(\delta+\rho)-\delta\right]
\end{aligned}
$$


of income shares. In a competitive economy, capital and labour are each paid their marginal products; that is, the marginal product of capital equals the rental rate, and the marginal product of labour equals the wage rate. In a competitive setting, the factor income shares are constant. This implies

$$
\begin{gathered}
\left(r^{A}\right)^{*}=1+\frac{\alpha \xi^{A} N}{\beta}-\delta \\
\left(r^{L}\right)^{*}=1+\frac{(1-\alpha) \xi^{L} N}{\theta}-\delta
\end{gathered}
$$

The wage rate in each industry, $w^{A}$ and $w^{L}$, equals the marginal product of the human capital, $u H^{A}$ (or $v H^{L}$ ) employed in the production of goods. Therefore, the two wage rates are

$$
\begin{gathered}
\left(w^{A}\right)^{*}=B^{A}(1-\beta)\left[\frac{1+\alpha \xi^{A} N}{\beta B^{A}}\right]^{\frac{1}{\beta-1}} \\
\left(w^{L}\right)^{*}=B^{L}(1-\theta)\left[\frac{1+(1-\alpha) \xi^{L} N}{\theta B^{L}}\right]^{\frac{1}{\theta-1}}
\end{gathered}
$$

If we plug the steady state values of the rental rates into equations (38a) and $(38 \mathrm{~b})$, we get the corresponding steady state growth rates. The steady state growth rate of $Y^{A}, C^{A}, K^{A}, H^{A}$ is given by $(47 a)$ :

$$
\gamma^{A}=\pi^{A}\left[1+\frac{\alpha \xi^{A} N}{\beta}-\delta-\rho\right]
$$

The steady state growth rate of $Y^{L}, C^{L}, K^{L}, H^{L}$ is given by $(47 b)$ :

$$
\gamma^{L}=\pi^{L}\left[1+\frac{(1-\alpha) \xi^{L} N}{\theta}-\delta-\rho\right]
$$




\section{Transitional Dynamics}

Equations (33a), (33b), (39a), (39b), (40a), and (40b) define a dynamic system for the variables $\omega^{i}(i=A, L), \chi^{i}(i=A, L), u$, and $v$. It is convenient, however, to work with transformed variables that are constant in the steady state. Thus, $\omega^{i}(i=A, L)$ is replaced by the gross average product of physical capital in the production of goods, denoted by $z^{i}(i=A, L)$.

$$
\begin{gathered}
z^{A} \equiv B^{A}\left(\omega^{A}\right)^{\beta-1} u^{1-\beta}=\frac{Y^{A}}{K^{A}} \\
z^{L} \equiv B^{L}\left(\omega^{L}\right)^{\theta-1} v^{1-\theta}=\frac{Y^{L}}{K^{L}}
\end{gathered}
$$

Unlike physical capital, $K^{i}(i=A, L)$, and consumption, $C^{i}(i=A, L)$, the gross average product of physical capital, $z^{i}(i=A, L)$, and the ratio of consumption to capital stock, $\chi^{i}(i=A, L)$, both approach constants in the steady state.

Equations (33a), (33b), (39a), (39b), (40a), and (40b) can be re-written in terms of the new variable, $z^{i}$, to give a new system of equations

$$
\begin{aligned}
& \frac{\dot{z^{A}}}{z^{A}}=-(1-\beta)\left[z^{A}-\left(z^{A}\right)^{*}\right] \\
& \frac{z^{L}}{z^{L}}=-(1-\theta)\left[z^{L}-\left(z^{L}\right)^{*}\right] \\
& \frac{\dot{\chi^{A}}}{\chi^{A}}=\left[z^{A}-\left(z^{A}\right)^{*}\right]\left(\pi^{A} \beta-1\right)+\left[\chi^{A}-\left(\chi^{A}\right)^{*}\right] \\
& \frac{\chi^{L}}{\chi^{L}}=\left[z^{L}-\left(z^{L}\right)^{*}\right]\left(\pi^{L} \theta-1\right)+\left[\chi^{L}-\left(\chi^{L}\right)^{*}\right] \\
& \frac{\dot{u}}{u}=\left(u-u^{*}\right)-\left[\chi^{A}-\left(\chi^{A}\right)^{*}\right] \\
& \frac{\dot{v}}{v}=\left(v-v^{*}\right)-\left[\chi^{L}-\left(\chi^{L}\right)^{*}\right]
\end{aligned}
$$


where $z^{i *}$ is the steady-state value of $z^{i}(i=A, L)$.

Using $\omega^{A *}, \omega^{L *}, \chi^{A *}, \chi^{L *}, u^{*}$, and $v^{*}$ as found earlier, along with the definitions of $z^{A}$ and $z^{L}$, we obtain the steady state values of $z^{A}$ and $z^{L}$ :

$$
\begin{gathered}
z^{A *}=\frac{1}{\beta}\left[1+\alpha \xi^{A} N\right] \\
z^{L *}=\frac{1}{\theta}\left[1+(1-\alpha) \xi^{L} N\right]
\end{gathered}
$$

Next we investigate the dynamics of the average product of physical capital, the rate of return, and the wage rate. The one-variable differential equations (49a) and (49b) determine the time paths of $z^{A}$ and $z^{L}$, respectively. These paths are linear. The equations can be solved in closed form. Integrating gives

$$
\begin{aligned}
& \frac{z^{A}-\left(z^{A}\right)^{*}}{z^{A}}=\left[\frac{z^{A}(0)-\left(z^{A}\right)^{*}}{z^{A}(0)}\right] e^{-(1-\beta)\left(z^{A}\right)^{*} t} \\
& \frac{z^{L}-\left(z^{L}\right)^{*}}{z^{L}}=\left[\frac{z^{L}(0)-\left(z^{L}\right)^{*}}{z^{L}(0)}\right] e^{-(1-\theta)\left(z^{L}\right)^{*} t}
\end{aligned}
$$

where $z^{i}(0)(i=A, L)$ is the initial value of the gross average product of physical capital. These equations can be solved for $z^{i}(i=A, L)$ :

$$
\begin{aligned}
z^{A} & =\frac{\left(z^{A}\right)^{*} z^{A}(0)}{\left(z^{A}\right)^{*} e^{-(1-\beta)\left(z^{A}\right)^{*} t}+z^{A}(0)\left[1-e^{-(1-\beta)\left(z^{A}\right)^{*} t}\right]} \\
z^{L} & =\frac{\left(z^{L}\right)^{*} z^{L}(0)}{\left(z^{L}\right)^{*} e^{-(1-\theta)\left(z^{L}\right)^{*} t}+z^{L}(0)\left[1-e^{-(1-\theta)\left(z^{L}\right)^{*} t}\right]}
\end{aligned}
$$

Equations (54a) and (54b) imply that $z^{A}$ and $z^{L}$ will adjust monotonically over time from $z^{A}(0)$ and $z^{L}(0)$, the initial values, to their steady state values, 
$\left(z^{i}\right)^{*}(i=A, L)$. When $z^{i}<\left(z^{i}\right)^{*}$, the growth rate of $z^{i}$ is positive, and $z^{i}$ increases toward its steady-state value. When $z^{i}>\left(z^{i}\right)^{*}$, the growth rate of $z^{i}$ is negative, and $z^{i}$ decreases toward its steady-state value. As $t \rightarrow \infty$, $z^{A} \rightarrow\left(z^{A}\right)^{*}$ and $z^{L} \rightarrow\left(z^{L}\right)^{*}$ if the steady-state value $z^{i *}$ is stable. The figure below provides a graphical representation of this stability property.

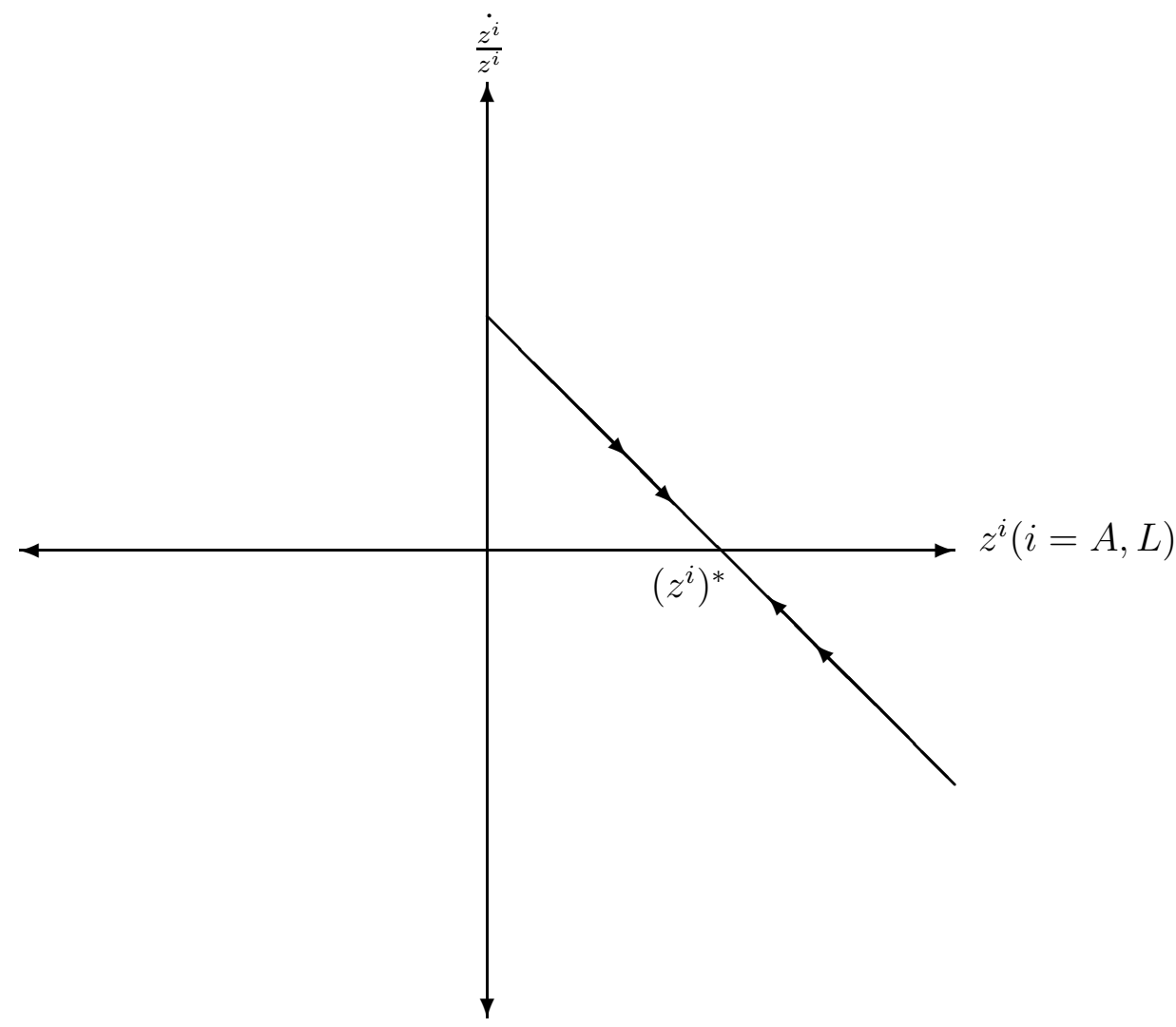

Figure 2 
The rates of return for both the advanced and laggard sectors can also be re-written in terms of the gross average product of physical capital in the production of the goods. They become $r^{A}=\beta z^{A}-\delta$ and $r^{L}=\theta z^{L}-\delta$ for the advanced and laggard industries, respectively. Thus, $z^{i}(i=A, L)$ determines $r^{i}(i=A, L)$. If $z^{i}(0)<\left(z^{i}\right)^{*}(i=A, L)$ then $r^{i}(0)<\left(r^{i}\right)^{*}(i=A, L)$, but if $z^{i}(0)>\left(z^{i}\right)^{*}(i=A, L)$ then $r^{i}(0)>\left(r^{i}\right)^{*}(i=A, L)$. As discussed earlier $z^{i}$ $(i=A, L)$ will rise (or fall) monotonically over time toward its steady-state value, which means that $r^{i}(i=A, L)$ will also rise (or fall) monotonically towards its steady-state value.

The wage rate in each sector, as mentioned earlier is equal to the marginal product of the human capital employed in the production of goods, $u H^{A}$ in the advanced sector, and $v H^{L}$ in the laggard sector. The wages rates can be re-written in terms of $z^{i}(i=A, L)$ to get;

$$
\begin{gathered}
w^{A}=B^{A}(1-\beta) u^{-\beta}\left(\omega^{A}\right)^{\beta}=\left(B^{A}\right)^{\frac{1}{1-\beta}}(1-\beta)\left(z^{A}\right)^{\frac{-\beta}{1-\beta}} \\
w^{L}=B^{L}(1-\theta) v^{-\theta}\left(\omega^{L}\right)^{\theta}=\left(B^{L}\right)^{\frac{1}{1-\theta}}(1-\theta)\left(z^{L}\right)^{\frac{-\theta}{1-\theta}}
\end{gathered}
$$

Therefore, if $z^{i}(0)<\left(z^{i}\right)^{*}(i=A, L)$ and $w^{i}(0)>\left(w^{i}\right)^{*}(i=A, L)$, $w^{i}(i=A, L)$ will follow $z^{i}(i=A, L)$ and fall monotonically over time towards the steady-state value. If $z^{i}(0)>\left(z^{i}\right)^{*}(i=A, L)$ and $w^{i}(0)<\left(w^{i}\right)^{*}$ $(i=A, L), w^{i}(i=A, L)$ will rise monotonically over time towards the steady-state.

Next we discuss the dynamics of $\chi^{A}$ and $\chi^{L}$. According to equations (50a) and (50b), the dynamics of $\chi^{A}$ and $\chi^{L}$ are dependent of the parameters $\pi^{A}, \pi^{L}, \beta$, and $\theta$. The variables $u$ and $v$ do not appear in equations (50a) and (50b), so a two-dimensional phase diagram can be constructed in $\left(z^{A}, \chi^{A}\right)$ space for the advanced sector, and $\left(z^{L}, \chi^{L}\right)$ space for the laggard sector. Two 
cases need to be considered for both the advanced and laggard sectors. The first case is if $\pi^{A} \beta<1$ for the advanced good and $\pi^{L} \theta<1$ for the laggard sector. The second case is the reverse, ie $\pi^{A} \beta>1$ and $\pi^{L} \theta>1$.

Case one: advanced sector $\pi^{A} \beta<1$ and laggard sector $\pi^{L} \theta<1$;

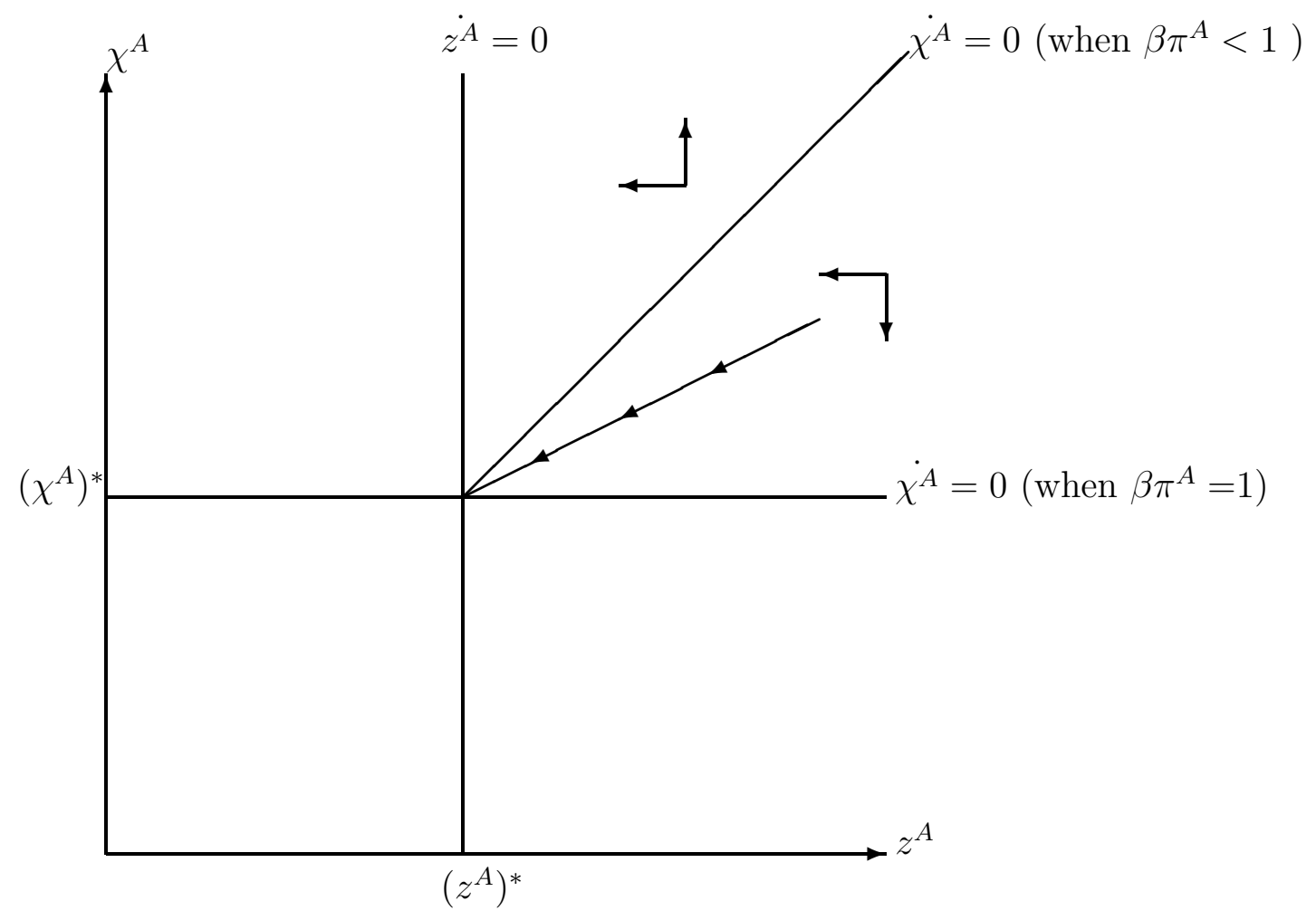

Figure 3

If $\chi^{i} \leq\left(\chi^{i}\right)^{*}(i=A, L)$ then $\dot{\chi}^{i}<0(i=A, L)$. Thus, $\chi^{i}(i=A, L)$ would diverge from $\left(\chi^{i}\right)^{*}(i=A, L)$ and reach zero. The stable path therefore has $\chi^{i}>\left(\chi^{i}\right)^{*}(i=A, L)$. If $\dot{\chi}^{i} \geq 0(i=A, L)$ for some $t$, then $\dot{\chi}^{i}>0$ for all subsequent $t$. The negative term $\left(\pi^{A} \beta-1\right)\left[z^{A}-\left(z^{A}\right)^{*}\right]$ for the advanced sector and $\left(\pi^{L} \theta-1\right)\left[z^{L}-\left(z^{L}\right)^{*}\right]$ for the laggard sector decreases in size over time. The variable $\chi^{i}(i=A, L)$ would diverge from $\left(\chi^{i}\right)^{*}(i=A, L)$ and 
approach $\infty$. The stable path is therefore $\dot{\chi}^{i}<0$ for all $t$.

Case two: advanced sector $\pi^{A} \beta>1$ and laggard sector $\pi^{L} \theta>1$;

The first terms in both equation (50a) and (50b) become positive.

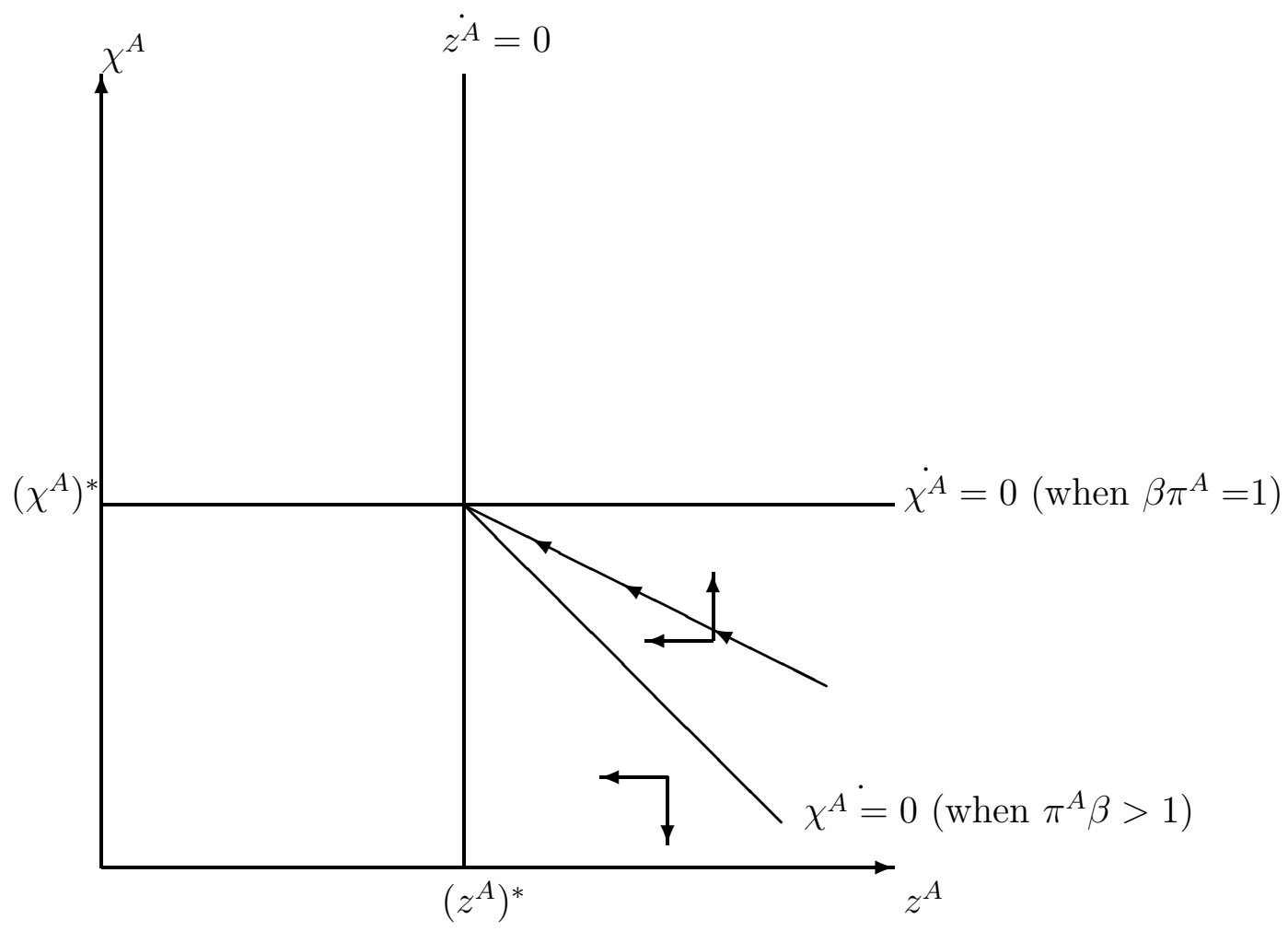

Figure 4

If $\chi^{i} \geq\left(\chi^{i}\right)^{*}(i=A, L)$ then $\dot{\chi}^{i}>0(i=A, L)$. Thus, $\chi^{i}(i=A, L)$ would diverge from $\left(\chi^{i}\right)^{*}(i=A, L)$ and approach $\infty$. The stable path therefore has $\chi^{i}<\left(\chi^{i}\right)^{*}(i=A, L)$. If $\dot{\chi}^{i} \leq 0(i=A, L)$ for some $t$, then $\dot{\chi}^{i}<0$ for all subsequent $t$. The positive term $\left(\pi^{A} \beta-1\right)\left[z^{A}-\left(z^{A}\right)^{*}\right]$ for the advanced sector and $\left(\pi^{L} \theta-1\right)\left[z^{L}-\left(z^{L}\right)^{*}\right]$ for the laggard sector decrease in size over time. The variable $\chi^{i}(i=A, L)$ would diverge from $\left(\chi^{i}\right)^{*}(i=A, L)$ and approach zero. The stable path is therefore $\dot{\chi}^{i}>0$ for all $t$. 
The dynamics of $u$ and $v$, the fractions of human capital used in production in the advanced and laggard sectors respectively are given by equations (51a) and (51b). The $\dot{u}=0$ and $\dot{v}=0$ loci are given by;

$$
\begin{aligned}
& u=u^{*}+\left[\chi^{A}-\left(\chi^{A}\right)^{*}\right] \\
& v=v^{*}+\left[\chi^{L}-\left(\chi^{L}\right)^{*}\right]
\end{aligned}
$$

Case one:

The locus is linear and upward sloping in $\left(u, \chi^{A}\right)$ space for the advanced sector [or $\left(v, \chi^{L}\right)$ space for the laggard sector] as shown below. In figure 5, $u\left(\chi^{A}\right)\left[\right.$ or $\left.v\left(\chi^{L}\right)\right]$ shows the stable saddle paths.

If $z^{i}(0)>\left(z^{i}\right)^{*}(i=A, L)$, then $\chi^{i}>\left(\chi^{i}\right)^{*}(i=A, L)$, and $\dot{\chi}^{i}<0$ $(i=A, L)$ as determined earlier. If for some $t, u \leq u^{*}$ (or $v \leq u^{*}$ for the laggard sector) then $\dot{u}<0$ (or $\dot{v}<0$ ) for all subsequent $t$. Therefore, $u$ (or $v$ ) moves from $u^{*}$ (or $v^{*}$ ) and approaches zero. Thus the stable path is $u>u^{*}$ (or $v>v^{*}$ ).

If $\dot{u} \geq 0$ (or $\dot{v} \geq 0$ for the laggard sector) for some $t$, then $\dot{u}>0$ (or $\dot{v}>0)$ for all subsequent $t$, because $-\left[\chi^{i}-\left(\chi^{i}\right)^{*}\right](i=A, L)$ is negative and decreasing in size. Therefore $\dot{u}<0$ (or $\dot{v}<0$ ) and $u>u^{*}$ (or $v>v^{*}$ ) holds for all $t$. 


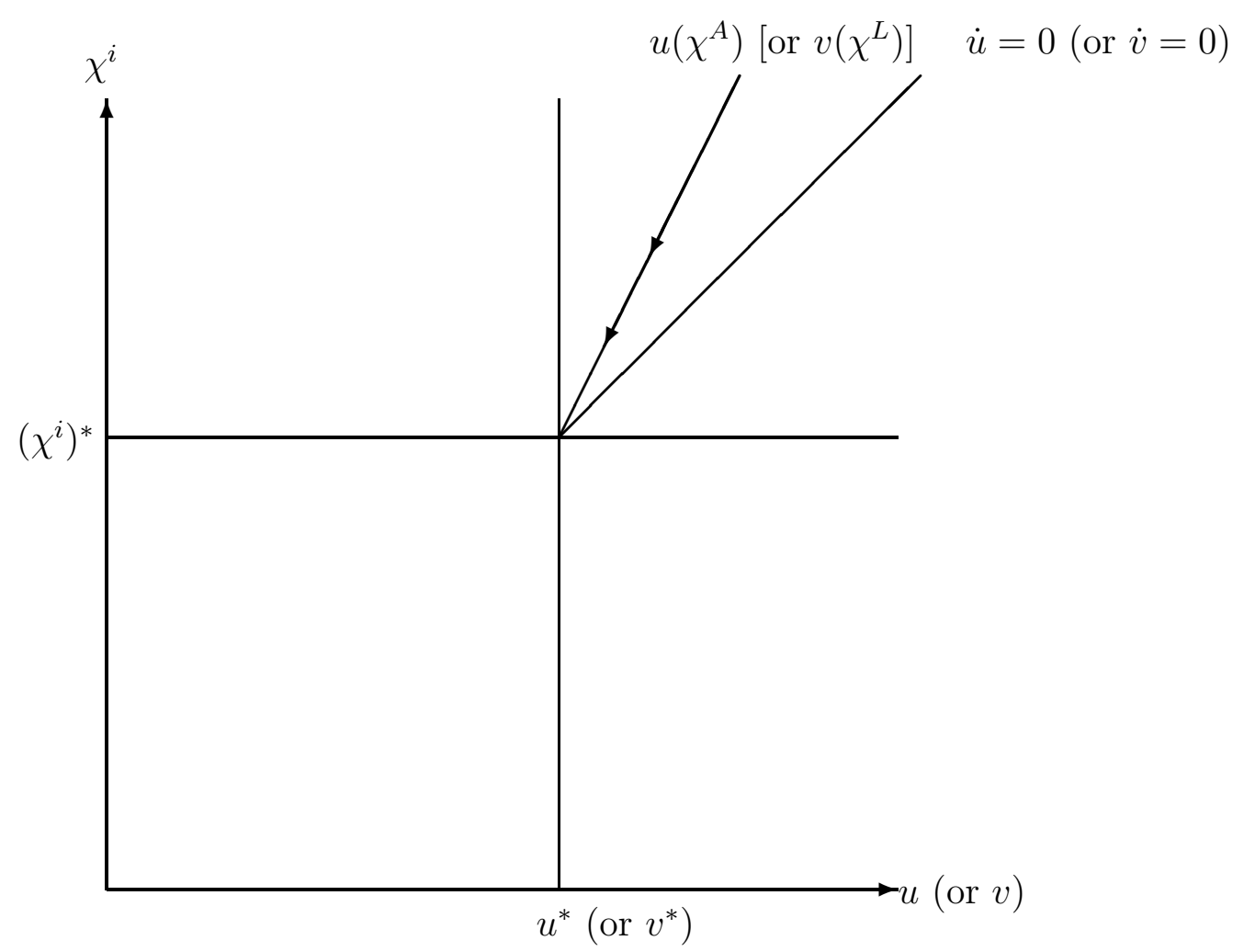

Figure 5

Case two:

If $z^{i}(0)(i=A, L)$, then $\chi^{i}<\left(\chi^{i}\right)^{*}, \dot{\chi}^{i}>0$. If for some $t, u \geq u^{*}$ (or $v \geq u^{*}$ for the laggard sector) then $\dot{u}>0$ (or $\dot{v}>0$ ) for all subsequent $t$. Therefore, $u$ (or $v$ ) moves from $u^{*}$ (or $v^{*}$ ) and approaches $\infty$. Thus the stable path is $u<u^{*}\left(\right.$ or $\left.v<v^{*}\right)$.

If $\dot{u} \leq 0$ (or $\dot{v} \leq 0$ for the laggard sector) for some $t$, then $\dot{u}<0$ (or $\dot{v}<0)$ for all subsequent $t$, because $-\left[\chi^{i}-\left(\chi^{i}\right)^{*}\right](i=A, L)$ is positive and decreasing in size. Therefore $\dot{u}>0$ (or $\dot{v}>0$ ) and $u<u^{*}\left(\right.$ or $v<v^{*}$ ) holds for all $t$. 


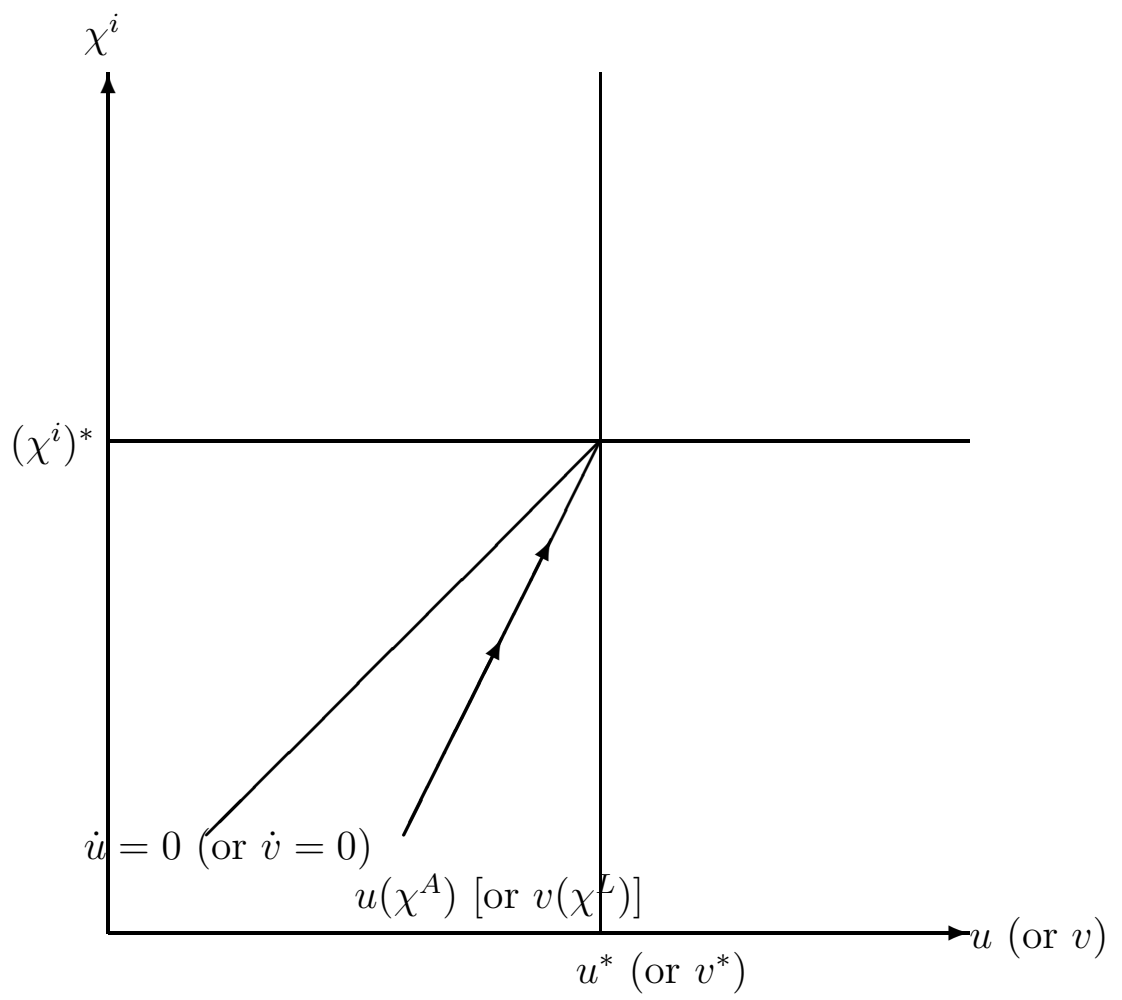

Figure 6 
It is also important to consider the relationship between $z^{i}(i=A, L)$, the gross average product of physical capital, and the state variable $\omega^{i}(i=A, L)$. The dynamics of $\omega^{A}$ and $\omega^{L}$ can be described by the following equations written in terms of $z^{i}(i=A, L)$;

$$
\begin{aligned}
\frac{\dot{\omega^{A}}}{\omega^{A}}= & z^{A}-\chi^{A}-(1-u)-\alpha \xi^{A} N \\
= & {\left[z^{A}-\left(z^{A}\right)^{*}\right]-\left[\chi^{A}-\left(\chi^{A}\right)^{*}\right]+\left(u-u^{*}\right)+1-\alpha \xi^{A} N } \\
& \frac{\dot{\omega^{L}}}{\omega^{L}}=z^{L}-\chi^{L}-(1-v)-(1-\alpha) \xi^{L} N \\
& {\left[z^{L}-\left(z^{L}\right)^{*}\right]-\left[\chi^{L}-\left(\chi^{L}\right)^{*}\right]+\left(v-v^{*}\right)+-\alpha \xi^{L} N }
\end{aligned}
$$

If we then use equations $(51 a)$ and $(51 b)$ to substitute in for $\left[\chi^{i}-\left(\chi^{i}\right)^{*}\right]$ $(i=A, L)$ we get;

$$
\begin{gathered}
\frac{\dot{\omega^{A}}}{\omega^{A}}=\pi^{A} \beta\left[z^{A}-\left(z^{A}\right)^{*}\right]-\gamma_{\chi^{A}}+\left(u-u^{*}\right)+\left(1-\alpha \xi^{A} N\right) \\
\frac{\dot{\omega^{L}}}{\omega^{L}}=\pi^{L} \theta\left[z^{L}-\left(z^{L}\right)^{*}\right]-\gamma_{\chi^{L}}+\left(v-v^{*}\right)+-\alpha \xi^{L} N
\end{gathered}
$$

If for case one $z^{i}(0)>\left(z^{i}\right)^{*}(i=A, L)$ then the conditions; $z^{i}-\left(z^{i}\right)^{*}>0$ $(i=A, L), \dot{\chi}^{i} \leq 0(i=A, L)$, and $u-u^{*} \geq 0$ (or $v-v^{*} \geq 0$ for laggard sector) imply that $\frac{\dot{\omega}^{A}}{\omega^{A}}>0$ (or $\frac{\dot{\omega}^{L}}{\omega^{L}}>0$ ). Hence, the system can only be on a stable path if $\omega^{i}(0)<\left(\omega^{A}\right)^{*}$. Then $\omega^{i}$ will rise monotonically from $\omega^{i}(0)$ towards $\left(\omega^{i}\right)^{*}$.

If for case one $z^{i}(0)<\left(z^{i}\right)^{*}(i=A, L)$ then the conditions; $z^{i}-\left(z^{i}\right)^{*}<0$ $(i=A, L), \dot{\chi}^{i} \geq 0(i=A, L)$, and $u-u^{*} \leq 0$ (or $v-v^{*} \leq 0$ for laggard sector) imply that $\frac{\dot{\omega}^{A}}{\omega^{A}}<0$. Hence, the system can only be on a stable path if $\omega^{i}(0)>\left(\omega^{A}\right)^{*}$. Then $\omega^{i}$ will fall monotonically from $\omega^{i}(0)$ towards $\left(\omega^{i}\right)^{*}$. 
Thus, $z^{i}$ and $\omega^{i}(i=A, L)$ are inversely related, with $z^{i}(0) \gtreqless\left(z^{i}\right)^{*}$ as $\omega^{i}(0) \lesseqgtr\left(\omega^{i}\right)^{*}$. A lower starting value of the state variable $\omega^{i}(i=A, L)$ is associated with a higher initial value of $z^{i}(0)$.

If we use equations (57a) and (57b) again, and use (50a) and (50b) to plug in an expression for $\left(u-u^{*}\right)$. we get;

$$
\begin{gathered}
\frac{\dot{\omega}^{A}}{\omega^{A}}=\left(z^{A}-\left(z^{A}\right)^{*}\right)+\gamma_{u}+\left(1-\alpha \xi^{A} N\right) \\
\frac{\dot{\omega^{L}}}{\omega^{L}}=\left(z^{L}-\left(z^{L}\right)^{*}\right)+\gamma_{v}+\left(-\alpha \xi^{L} N\right)
\end{gathered}
$$

For case two, if $z^{i}(0)>\left(z^{i}\right)^{*}($ for $i=A, L)$ then: $\dot{u}>0$ and $z^{A}<0$. This implies that $\frac{\dot{\omega}^{A}}{\omega^{A}}>0$. However, if $z^{i}(0)<\left(z^{i}\right)^{*}$, then $\dot{u}<0$ and $z^{A}<0$. This implies $\frac{\dot{\omega}^{A}}{\omega^{A}}<0$. Therefore $\omega^{i}$ (for $i=A, L$ ) is always inversely related to $z^{i}$.

When case one holds, the policy functions for $\chi^{A}$ and $u$ for the advanced sector are both downward sloping functions of $\omega^{A}$. Similarly, for the laggard sector both $\chi^{L}$ and $v$ are downward sloping functions of $\omega^{L}$. This is illustrated by figures 7 and 8 below. 


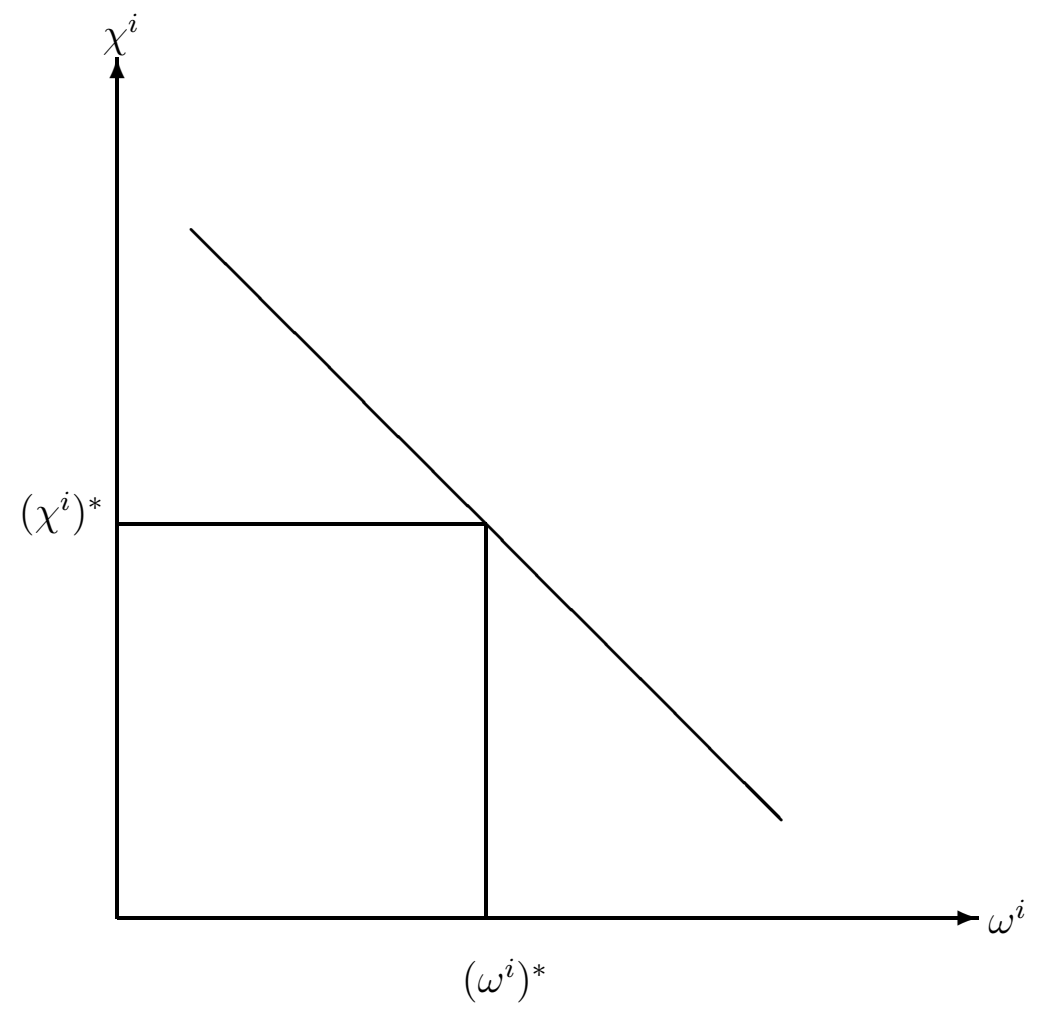

Figure 7 


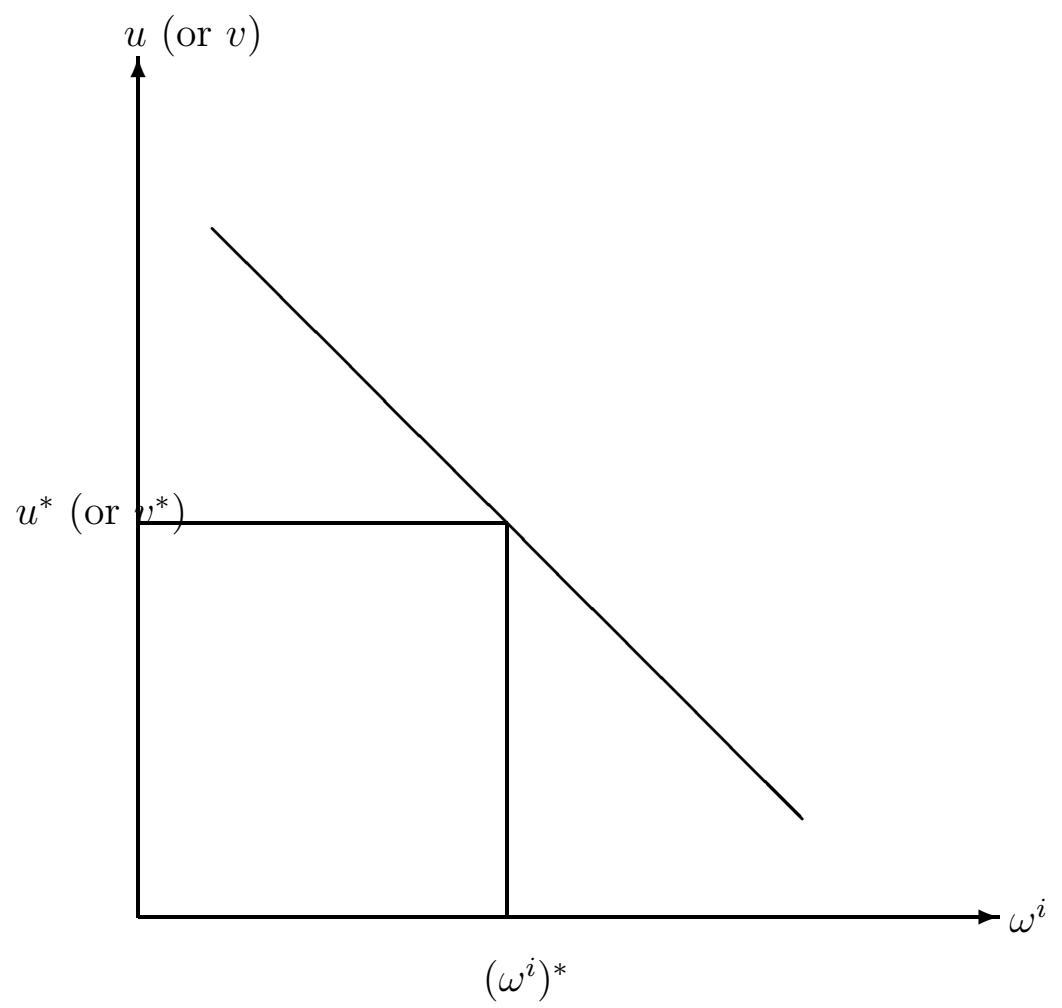

Figure 8

If an economy is in an initial state with a relative scarcity of human capital, ie $\omega^{i}(0)>\left(\omega^{i}\right)^{*}$, then $\omega^{i}$ will fall over time, whilst $\chi^{i}$ and $u$ and $v$ will rise. This means that in the beginning the economy will allocate a relatively small proportion of its resources to consumption, ie $\chi^{i}$ is low. However, the economy will spend a large proportion of its time on educating, ie $(1-u)$ or $(1-v)$ is high.

If case two holds, then both policy functions will be upward sloping, as seen in figures 9 and 10. 


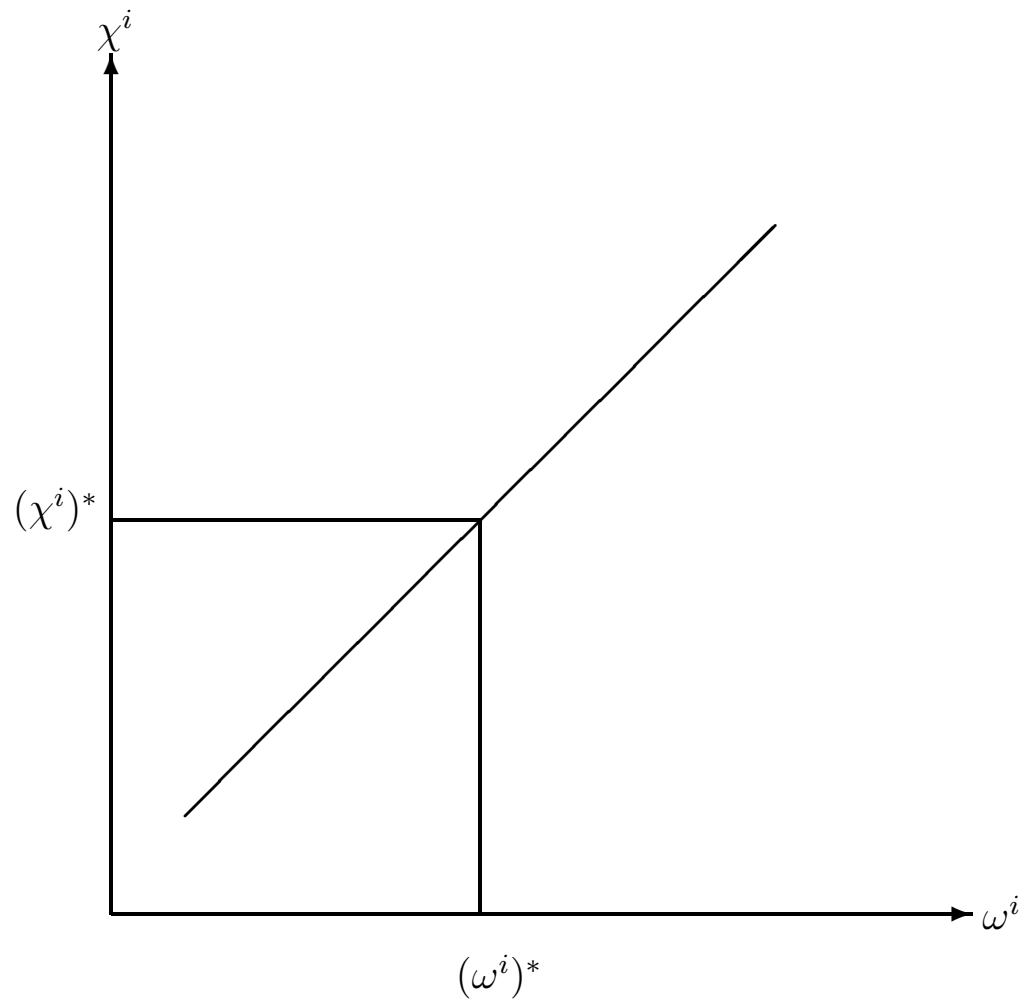

Figure 9 


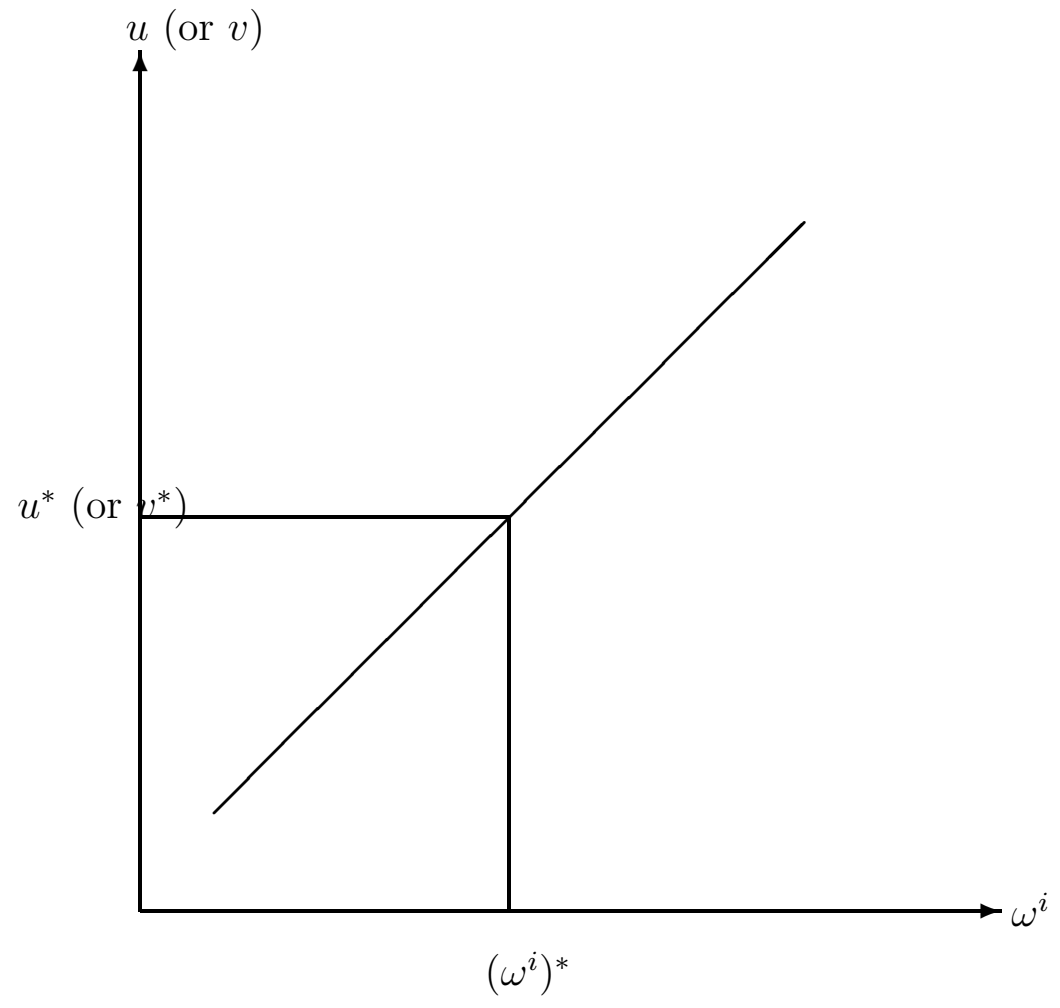

Figure 10 
The transitional dynamics of the growth rates of consumption, human capital, physical capital, $u$ and $v$ will depend on the initial values of $\omega^{A}$ and $\omega^{L}$. If the economy begins with $\omega^{i}<\left(\omega^{i}\right)^{*}(i=A, L)$, the rates of return $r^{i}$, as mentioned earlier, will decline monotonically toward $\left(r^{i}\right)^{*}$. Using equations $(38 a)$ and $(38 b)$ we see that this fall in $r^{i}$ implies a decline in $\frac{\dot{c}^{i}}{c^{i}}$. If $\omega^{i}>\left(\omega^{i}\right)^{*}$ then $r^{i}$ will increase monotonically toward $\left(r^{i}\right)^{*}$. This rise implies an increase in $\frac{c^{i}}{c^{i}}$. This relationship is illustrated graphically in figure 11 .

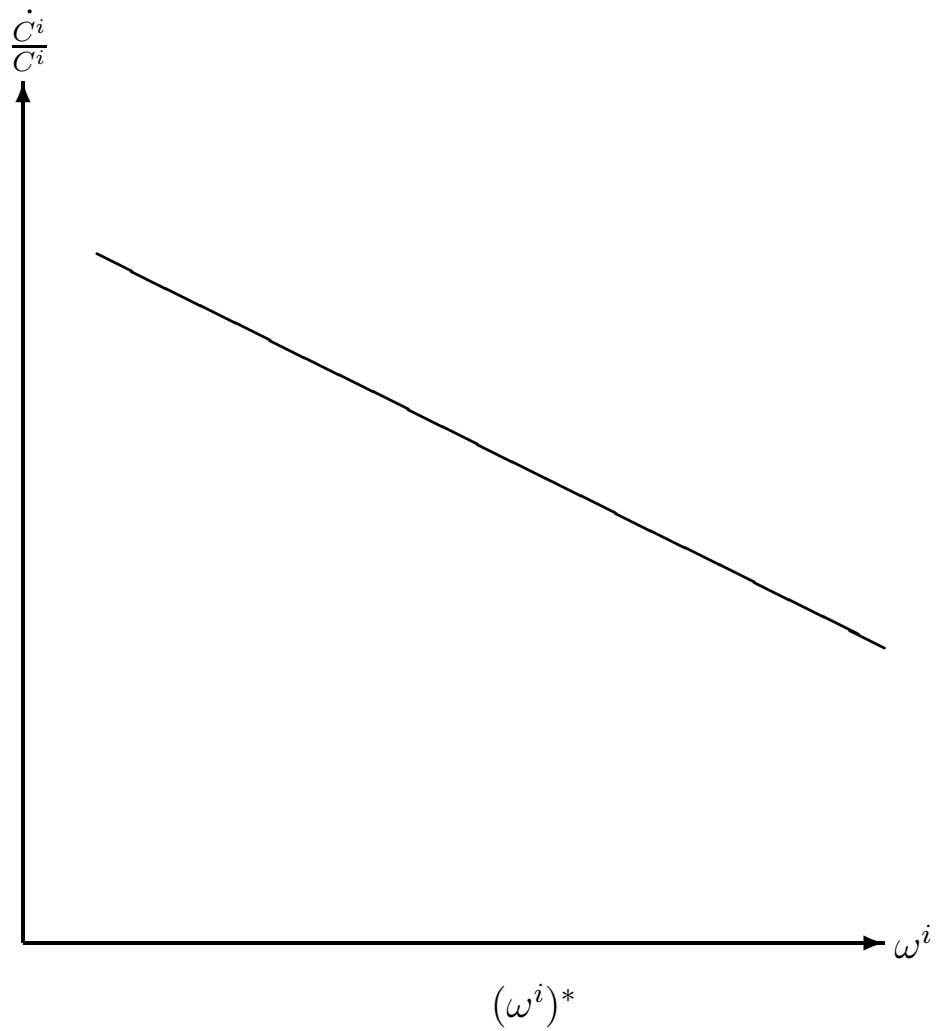

Figure 11 
The growth rates of the stocks of physical capital are obtained by substituting $\frac{\dot{c^{i}}}{c^{i}}(i=A, L)$ from equations $(38 a)$ and $(38 b)$.

$$
\begin{aligned}
& \frac{\dot{K^{A}}}{K^{A}}=\frac{\dot{C}^{A}}{C^{A}}-\frac{\dot{\chi^{A}}}{\chi^{A}}=\pi^{A}\left[\beta z^{A}-\delta-\rho\right]-\frac{\dot{\chi^{A}}}{\chi^{A}} \\
& \frac{\dot{K^{L}}}{K^{L}}=\frac{\dot{C^{L}}}{C^{L}}-\frac{\dot{\chi^{L}}}{\chi^{L}}=\pi^{L}\left[\theta z^{L}-\delta-\rho\right]-\frac{\dot{\chi^{L}}}{\chi^{L}}
\end{aligned}
$$

Equations $(57 a)$ and $(57 b)$ then are used to substitute for $\frac{\dot{\chi}^{i}}{\chi^{i}}(i=A, L)$. Finally, using equations (51a) and (51b), we get;

$$
\begin{aligned}
& \frac{\dot{K}^{A}}{K^{A}}=\left(\gamma^{A}\right)^{*}+\left[z^{A}-\left(z^{A}\right)^{*}\right]-\left[\chi^{A}-\left(\chi^{A}\right)^{*}\right] \\
& \frac{\dot{K}^{L}}{K^{L}}=\left(\gamma^{L}\right)^{*}+\left[z^{L}-\left(z^{L}\right)^{*}\right]-\left[\chi^{L}-\left(\chi^{L}\right)^{*}\right]
\end{aligned}
$$

where $\left(\gamma^{A}\right)^{*} \equiv \pi^{A}\left[\beta\left(z^{A}\right)^{*}-\delta-\rho\right]$ and $\left(\gamma^{L}\right)^{*} \equiv \pi^{L}\left[\theta\left(z^{L}\right)^{*}-\delta-\rho\right]$

Equations $(61 a)$ and $(61 b)$ tell us that the growth rates of the physical capitals, under case one, move ambiguously with respect to $\omega^{i}$. If $z^{i}>\left(z^{i}\right)^{*}$ then the second terms in the equations are positive, but the last terms are negative.

However, if case two holds and $z^{i}>\left(z^{i}\right)^{*}$, then the second terms in the equations will be positive and the last terms will also be positive. Thus, $\frac{\dot{K}^{i}}{K^{i}}$ will be increasing in $\omega^{i}$. 


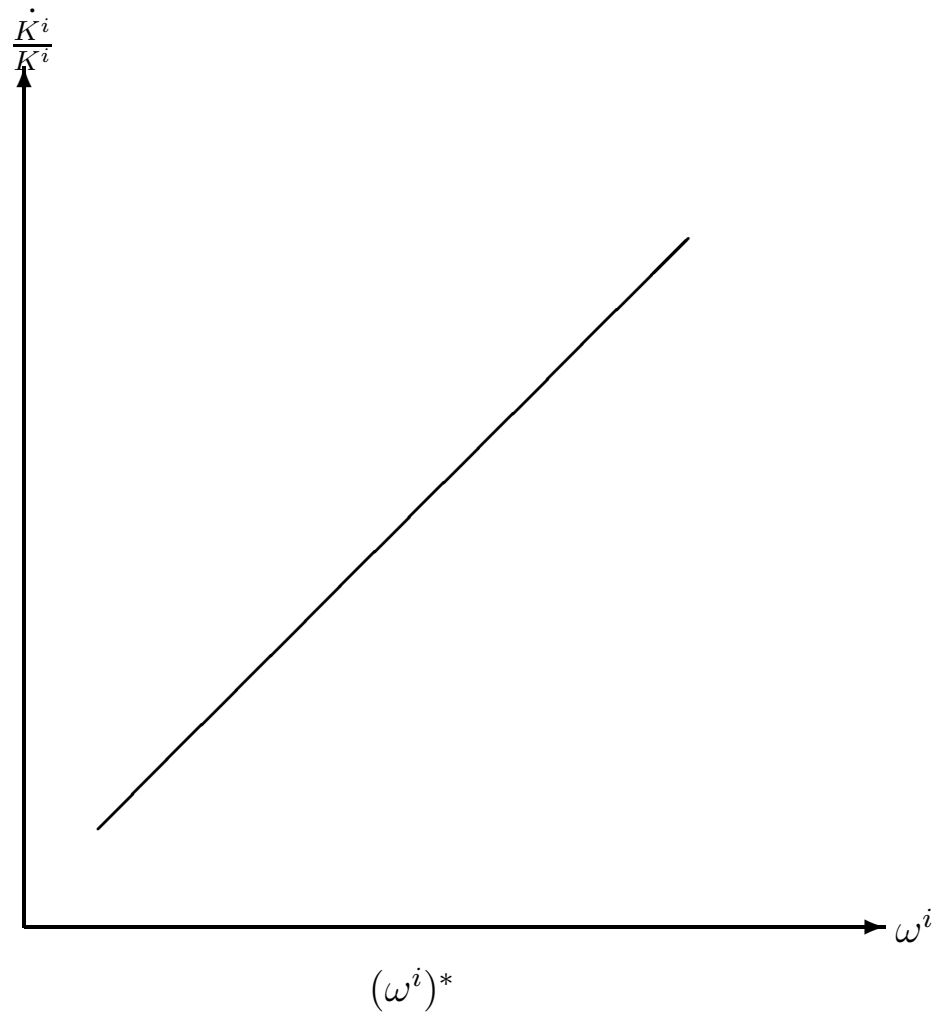

Figure 12 
The growth rates of the stocks of human capital are given by;

$$
\begin{aligned}
& \frac{\dot{H}^{A}}{H^{A}}=\frac{\dot{K}^{A}}{K^{A}}-\frac{\dot{\omega}^{A}}{\omega^{A}} \\
& \frac{\dot{H}^{L}}{H^{L}}=\frac{\dot{K^{L}}}{K^{L}}-\frac{\dot{\omega}^{L}}{\omega^{L}}
\end{aligned}
$$

If we use equations $(61 a),(61 b),(59 a),(59 b),(51 a)$, and (51b) we get;

$$
\begin{gathered}
\frac{\dot{H^{A}}}{H^{A}}=\left(\gamma^{A}\right)^{*}-\left(u-u^{*}\right)+\left(1-\alpha \xi^{A} N\right) \\
\frac{\dot{H^{L}}}{H^{L}}=\left(\gamma^{L}\right)^{*}-\left(v-v^{*}\right)+\left(1-(1-\alpha) \xi^{L} N\right)
\end{gathered}
$$

If case one holds, then equations $(63 a)$ and (63b) imply that $\frac{\dot{H^{i}}}{H^{i}}(i=A, L)$ is increasing in $\omega^{i}$ because, as figure 8 shows, $\left(u-u^{*}\right)$ and $\left(v-v^{*}\right)$ are declining in $\omega^{i}$. 


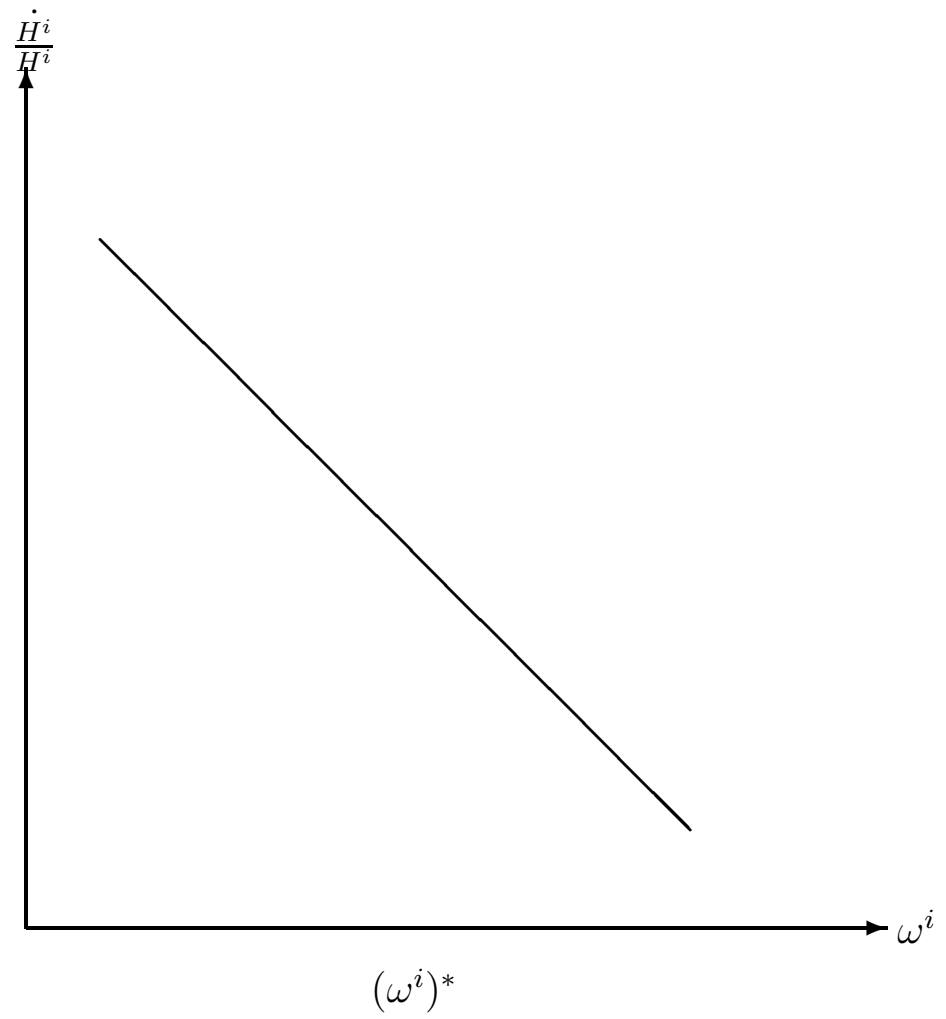

Figure 13

Figure 13 shows the positive relationship between the growth rate of $H^{i}$ and $\omega^{i}$. 
However, if case two holds, $\frac{\dot{H^{i}}}{H^{i}}(i=A, L)$ is decreasing in $\omega^{i}$ because, as figure 10 shows, $\left(u-u^{*}\right)$ and $\left(v-v^{*}\right)$ are increasing in $\omega^{i}$.

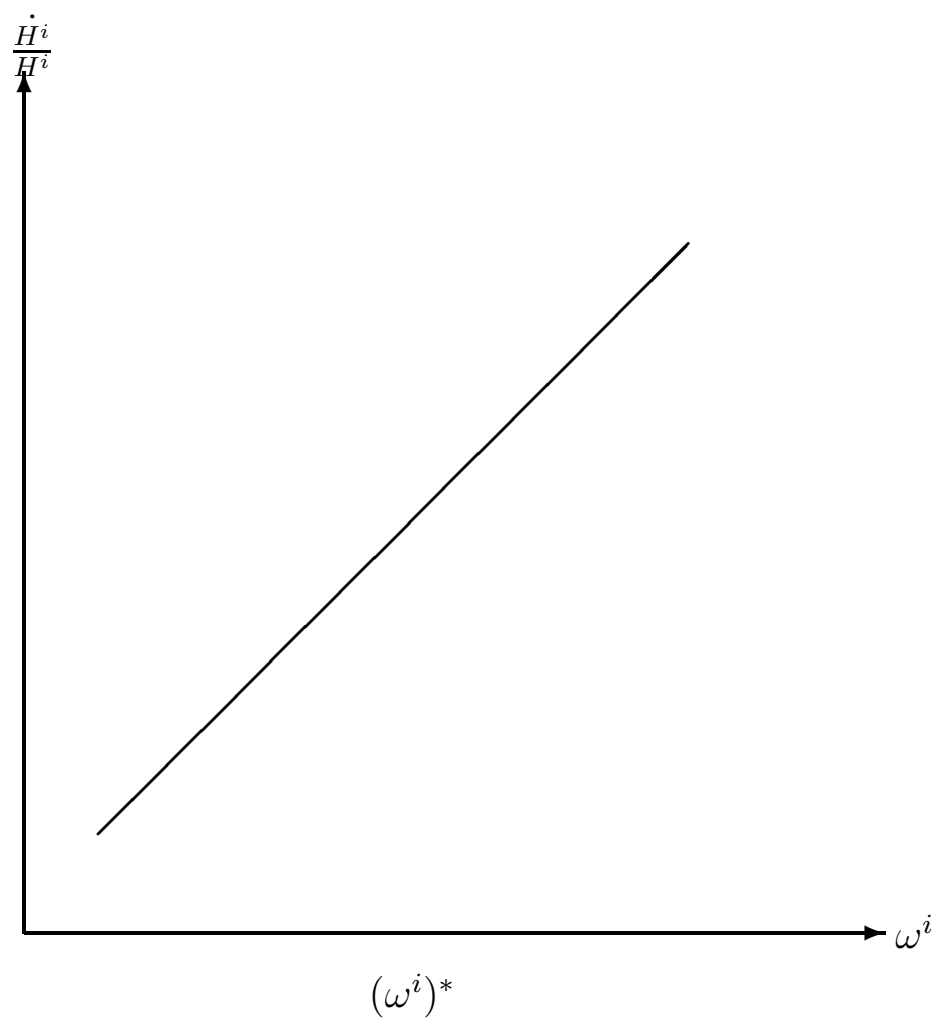

Figure 14 


\section{Simulation}

The more general case is discussed in section 3. In the special case is if there is no new entries (ie $N=0$ ), then our model will be similar to that of the generalized Uzawa-Lucas model. Barro (2004) carried out some simulations for the generalized Uzawa-Lucas model with two sectors. We adopt his parameter values $\beta=\theta=0.4$, while the parameters $\phi$ and $\mu$ are varied between 0 and 0.4 . As a representative case; $\delta=0.05, \rho=0.02$, and $\sigma=3$. For $\phi=\mu=0$ and $B^{i}$ normalized to one, Barro found that the steady state interest rate is 0.08 and the steady-state growth rate is 0.02 .

In our simulation with new entries, we use Barros parameter values. The number of new entries is normalized to one: $N=1$. The human capital contributions in each sector is set equal: $\xi^{A}=\xi^{L}=0.9$.

Half of the new entries go to the advanced sector: $\alpha=0.5$. This is a realistic representation of the television industry, as there is a similar number of new entries in both plasma and LCD markets. Finally, $C^{L}=0.8$ and $C^{A}=0.2$. This also reflects the television market, as the sale of plasmas are significantly greater than the sale of LCDs in the larger screen sizes.

We obtained the following results. The steady state interest rates are $r^{A}=$ $r^{L}=0.12711902$. The steady state growth rate for the advanced sector is $\gamma^{A}=0.0856$ and for the laggard sector is $\gamma^{L}=0.04686$. These steady state growth rates are much higher than the 0.02 found in the standard model with no new entries. Our results are consistent with the empirical evidence that growth rates increase with new entries, as established in our model.

If there are no new entries $(\mathrm{N}=0)$ then the results are the same as in Lucas (1993). If $N>0$, the fraction of human capital devoted to human capital accumulation is increasing with new entries. That is, $(1-u)$ and $(1-v)$ are positively related to new entries. 
We assume that both $\xi^{A}$ and $\xi^{L}$ are less than one. When $\alpha$ is set to 0.5 , both markets have the same number of new entries. The contribution of new entries into the advanced market $\left(\xi^{A}\right)$ is assumed to be the same as that in the laggard market $\left(\xi^{L}\right)$. Also, the parameters $\theta$ and $\beta$ are set equal, so production in the advanced and laggard sectors is equally intensive in physical and human capital. Then, for the fraction of human capital devoted to human capital accumulation in the advanced good, $1-u$, to be greater than that of the laggard good, $1-v, \pi^{A}$ must be greater than $\pi^{L}$.

Because $\lambda$ is less than one, the value of $C^{L}$ needs to be sufficiently larger than $C^{A}$. For the case of the flat screen televisions; plasma and LCDs are relatively close substitutes, so $\lambda$ will be closer to one. Currently, plasma televisions dominate the market of the larger screens because of their lower prices, so $C^{L}>C^{A}$. This implies that $u<v$, which is consistent with the empirical evidence of hetrogenity between laggard and advanced firms presented in Aghion (2006).

The intuition for this result is that the advanced sector will invest more into education and knowledge when the threat of new entries is increased. It is similar to the escape entry effect in Aghion et al, where the advanced incumbents invest to protect their market share. The effect of increased entry on the laggard sectors will still be positive, but much weaker than that in the advanced sector.

If $\pi^{A}$ is larger than $\pi^{L}$ and the other parameters are as described above, $\omega^{A}$ will be larger than $\omega^{L}$. This means that the proportion of physical to human capital used to produce advanced goods is larger than that for the laggard good. $\pi^{A}>\pi^{L}$ also implies that $\chi^{A}$ will be greater than $\chi^{L}$. This means that the growth rate in the advanced sector will be higher than that in the laggard sector. 


\section{Conclusion}

This thesis investigates the effects of new entry on growth in an economy with advanced and laggard sectors. The theoretical model has four sectors with four Cobb-Douglas production functions.

The main result of the model is that new entries have a positive effect on the fraction of human capital devoted to the accumulation of human capital in both the advanced and laggard sectors. However, under certain conditions, this effect is much stronger in the advanced sector than in the laggard sector. Thus, new entries have a larger impact on growth in the advanced sector than in the laggard sector.

However, one weakness of this model that is shared by the bulk of the existing literature is that we study a closed economy. This is not a accurate reflection of the real world. One possible direction for future research would be to have an open economy allowing for imports and exports. Another possible extension is to include leisure in the utility function, similar to the extension in Lucas (1988). 


\section{References}

Aghion, P., N. Bloom, R. Blundell, R. Griffith, and P. Howwit, Competition and Innovation: An Inverted-U Relationship, Quarterly Journal of Economics, Vol. 120 (2005) 701-728

Aghion, P., R. Blundell, R. Griffith, P. Howitt, S. and Prantl, The Effect of Entry on Incumbent Innovation and Productivity, NBER Working Paper Series 12027 (2006)

Aghion, P., C. Harris, P. Howitt, and J. Vickers, Competition, Imitation and Growth with Step-by-Step Innovation, The Review of Economic Studies, Vol. 68, No.3. (2001),467-492

Aghion, P., C. Harris, and J. Vickers, Competition and Growth with Stepby-Step Innovation: An Example, European Economic Review, Vol. 41 (1997), 771-782

Aghion, P. and P. Howitt, Endogenous Growth Theory, The MIT Press (1998)

Barro, R. J. and X. Sala-i-Martin, Economic Growth Second Edition, Cambridge, MA: MIT Press (2004)

Bond, E. W. and P. Wang. A General Two-Sector Model of Endogenous Growth with Human and Physical Capital: Balanced Growth and Transitional Dynamics, Journal of Economic Theory, Vol. 68 (1996), 149173

de Hek, P. A. On Endogenous Growth under Uncertainty, International Economic Review, Vol. 40, No.3 (1999), 727-744 
Dixit, A. K. and J. E. Stiglitz, Monopolistic Competition and Optimum Product Diversity, The American Economic Review, Vol.67, No.3. (1977), 297-308

Geroski, P. A. What do we know about entry? International Journal of Industrial Organization, Vol. 13 (1995), 421-440

Grossman, G. M. and E. Helpman, Innovation and Growth in the Global Economy, Cambridge, MA, MIT Press, (1999)

Grossman, G. M. and E. Helpman, Quality Ladders and Product Cycles, The Quarterly Journal of Economics, Vol. 106 (1991) 557-586

Harris, C. and J. Vickers, Racing with Uncertainty, Review of Economic Studies, Vol. 54 (1987), 1-21

Jones, C. I. With or Without Scale Effects? The American Economic Review, Vol. 89, No. 2 (1999), 139-144

Lucas, R. E. On the Mechanics of Economic Development, Journal of Monetary Economics, Vol. 22 (1988), 3-42

Rebelo, S. Long-RUn Policy Analysis and Long-Run Growth, Journal of Political Economy, Vol. 3 (1999), 500-521

Romer, P. M. Endogenous Technological Change, The Journal of Political Economy, Vol. 98 (1990), 71-102

Display Search, www.displaysearch.com (2008) 